\title{
Linalool inhibits the angiogenic activity of endothelial cells by downregulating intracellular ATP levels and activating TRPM8
}

\author{
Vivien Becker ${ }^{1}$. Xin Hui ${ }^{2}$ - Lisa Nalbach ${ }^{1}$ - Emmanuel Ampofo ${ }^{1} \cdot$ Peter Lipp $^{2}$ - Michael D. Menger ${ }^{1}$. \\ Matthias W. Laschke ${ }^{1}$ Yuan $\mathrm{Gu}^{1}$ (1)
}

Received: 25 May 2020 / Accepted: 10 February 2021 / Published online: 2 March 2021

(c) The Author(s) 2021

\begin{abstract}
Angiogenesis crucially contributes to various diseases, such as cancer and diabetic retinopathy. Hence, anti-angiogenic therapy is considered as a powerful strategy against these diseases. Previous studies reported that the acyclic monoterpene linalool exhibits anticancer, anti-inflammatory and anti-oxidative activity. However, the effects of linalool on angiogenesis still remain elusive. Therefore, we investigated the action of (3R)-(-)-linalool, a main enantiomer of linalool, on the angiogenic activity of human dermal microvascular endothelial cells (HDMECs) by a panel of angiogenesis assays. Non-cytotoxic doses of linalool significantly inhibited HDMEC proliferation, migration, tube formation and spheroid sprouting. Linalool also suppressed the vascular sprouting from rat aortic rings. In addition, Matrigel plugs containing linalool exhibited a significantly reduced microvessel density 7 days after implantation into BALB/c mice. Mechanistic analyses revealed that linalool promotes the phosphorylation of extracellular signal-regulated kinase (ERK), downregulates the intracellular level of adenosine triphosphate (ATP) and activates the transient receptor potential cation channel subfamily M (melastatin) member (TRPM)8 in HDMECs. Inhibition of ERK signaling, supplementation of ATP and blockade of TRPM8 significantly counteracted linalool-suppressed HDMEC spheroid sprouting. Moreover, ATP supplementation completely reversed linalool-induced ERK phosphorylation. In addition, linalool-induced ERK phosphorylation inhibited the expression of bone morphogenetic protein (BMP)-2 and linalool-induced TRPM8 activation caused the inhibition of $\beta 1$ integrin/focal adhesion kinase (FAK) signaling. These findings indicate an anti-angiogenic effect of linalool, which is mediated by downregulating intracellular ATP levels and activating TRPM8.
\end{abstract}

Keywords Linalool $\cdot$ Endothelial cells · TRPM8 $\cdot$ ATP $\cdot$ Angiogenesis $\cdot$ Vascularization

\section{Introduction}

Angiogenesis is a highly dynamic process, which is defined as the development of new blood vessels from preexisting ones. During this process, endothelial cells (ECs) are activated by pro-angiogenic factors, such as vascular endothelial growth factor (VEGF) and basic fibroblast growth factor (bFGF), to proliferate, migrate and form new microvascular networks [1]. These activities of ECs are mediated by

Yuan Gu

yuan.gu@uks.eu

1 Institute for Clinical \& Experimental Surgery, Saarland University, 66421 Homburg, Saarland, Germany

2 Molecular Cell Biology, Research Center for Molecular Imaging and Screening, Medical Faculty, Saarland University, 66421 Homburg, Saarland, Germany several pivotal angiogenesis-related pathways, including phosphatidylinositol 3-kinase (PI3K)/AKT/mammalian target of rapamycin (mTOR) and Raf/mitogen-activated protein kinase (MEK)/extracellular signal-regulated kinase (ERK) signaling [2,3]. Notably, ERK has also been reported to be activated by different stress stimuli, such as oxidative stress and DNA damage stimuli, and suppress cell proliferation and survival [4-7].

Recently, Genova et al. demonstrated an inhibitory effect of transient receptor potential cation channel subfamily $\mathrm{M}$ (melastatin) member 8 (TRPM8) on EC adhesion, migration, tube formation and spheroid sprouting [8]. TRPM8, also known as the cold and menthol receptor 1 (CMR1), is the main molecular transducer of cold somatosensation in humans. It can be activated by voltage, cold temperatures and cooling compounds, such as menthol and icilin [9-11]. Upon activation, sodium and calcium ions pass through 
TRPM8 channels into cells to regulate various cellular processes [12]. Of interest, Genova et al. reported that TRPM8 inhibits EC motility independently of pore function, but retains Rap1 GTPase through direct protein-protein interaction [8].

Angiogenesis occurs during embryogenesis and wound healing. On the other hand, the development of new blood vessels is critically involved in a large number of diseases, including cancer, endometriosis, psoriasis and diabetic retinopathy [13]. Accordingly, the inhibition of angiogenesis represents a promising strategy for the treatment of these diseases. So far, the United States Food and Drug Administration has approved several anti-angiogenic agents targeting the VEGF/VEGF receptor pathway [14]. Unfortunately, these agents are quite expensive and frequently induce severe side effects during long-term treatment. Therefore, there is an urgent need for the development of novel antiangiogenic drugs with fewer side effects.

Phytochemicals are considered as a rich source for the discovery of new compounds, which are cheap, effective and safe. Such a compound is linalool, a main active ingredient of essential oils of various aromatic species, including lavender, orange and rose. Actually, linalool is produced by over 200 different plant species and also found in some fungi [15]. It is widely used as a fragrance ingredient in shampoos, body lotions, perfume and soaps. Moreover, it is also commonly used as a flavoring in beverages and foods [15]. Previous studies reported a broad spectrum of biological activities for linalool, including sedative, analgesic, anticancer, antioxidant, antimicrobial and anti-inflammatory properties $[16,17]$. However, so far nothing is known about its effects on angiogenesis.

Therefore, the aim of the present study was to investigate the action of (3R)-(-)-linalool on the proliferation, migration, tube formation and spheroid sprouting of human dermal microvascular endothelial cells (HDMECs). To validate our in vitro findings, we additionally performed an ex vivo aortic ring assay and an in vivo Matrigel plug assay. Moreover, we analyzed the effects of linalool on angiogenesis-related signaling pathways, intracellular levels of adenosine triphosphate (ATP), reactive oxygen species (ROS) formation and TRPM8 activity in HDMECs. In addition, the downstream anti-angiogenic mediators of linalool-induced ATP reduction and TRPM8 activation were identified.

\section{Materials and methods}

\section{Cell culture and treatment}

HDMECs (PromoCell, Heidelberg, Germany) were cultured in endothelial cell growth medium (EGM)-MV (PromoCell) and incubated at $37{ }^{\circ} \mathrm{C}$ in a humidified atmosphere containing $5 \% \mathrm{CO}_{2}$. A stock solution of $5 \mathrm{M}(3 R)-(-)$ linalool (Sigma-Aldrich, Darmstadt, Germany) was prepared in dimethyl sulfoxide (DMSO) and further diluted into different concentrations $(0.05-5 \mathrm{mM})$ in EGM-MV. The DMSO concentrations were identical in the linalool- and vehicle-treated groups. The cells were exposed to linalool for $24 \mathrm{~h}$ followed by different in vitro assays.

\section{Cell transfection}

To downregulate the expression level of ERK and TRPM8, HDMECs were transfected for $48 \mathrm{~h}$ with $20 \mathrm{nM}$ small interfering RNAs (siRNAs) against ERK1/2 (si-ERK; Cell Signaling Technology, Frankfurt, Germany) or $120 \mathrm{nM}$ siRNAs against TRPM8 (si-TRPM8; ON-TARGETplus siRNA SMARTpool, Dharmacon, Colorado, USA) using HiPerFect reagent (Qiagen, Hilden, Germany) according to the manufacturer's protocol. Negative control of siRNA (si-NC, Qiagen) served as control.

\section{Water-soluble tetrazolium (WST)-1 assay}

Cell viability was assessed by a WST- 1 assay, in which tetrazolium salt is converted into soluble formazan by mitochondrial dehydrogenase. The amount of produced formazan depends on the number of viable cells. As described previously [18], $5 \times 10^{3}$ HDMECs were seeded in each well of 96-well plates and exposed to different compounds for $24 \mathrm{~h}$. Then, $10 \mu \mathrm{L}$ WST-1 reagent (Roche Diagnostics, Mannheim, Germany) was added into each well and the plate was incubated at $37^{\circ} \mathrm{C}$ for $30 \mathrm{~min}$. The absorbance of each well was measured at $450 \mathrm{~nm}$ with $620 \mathrm{~nm}$ as reference using a microplate photometer (PHOmo; anthos Mikrosysteme GmbH, Krefeld, Germany).

\section{Lactate dehydrogenase (LDH) assay}

The cytotoxicity of linalool was analyzed by a LDH assay according to the manufacturer's instructions (Roche Diagnostics). Briefly, $5 \times 10^{3}$ HDMECs were seeded in each well of 96-well plates and exposed for $24 \mathrm{~h}$ to different concentrations of linalool. Then, $100 \mu \mathrm{L}$ LDH reaction mix was added into each well. After 10 min of incubation at room temperature, the reaction was stopped by addition of $50 \mu \mathrm{L}$ stop solution. The absorbance of each well was then measured at $492 \mathrm{~nm}$ with $620 \mathrm{~nm}$ as reference using a microplate photometer (PHOmo).

\section{Flow cytometry}

The effects of linalool on EC proliferation, ROS formation and $\beta 1$ integrin activation were analyzed by means of flow cytometry. 
To assess cell proliferation, a bromodeoxyuridine (BrdU) assay was performed. Briefly, HDMECs seeded in $60-\mathrm{mm}$ dishes were exposed to different concentrations of linalool for $6 \mathrm{~h}$ followed by BrdU addition and incubation for another $18 \mathrm{~h}$. Then, the cells were fixed with $70 \%$ ethanol for $30 \mathrm{~min}$ on ice and incubated with $2 \mathrm{M}$ hydrochloric acid $(\mathrm{HCl})$ containing $0.5 \%$ Triton-X 100 for $30 \mathrm{~min}$ at room temperature for DNA denaturation. After incubation with a fluorescein isothiocyanate (FITC)-labeled anti-BrdU antibody (1:50; Thermo Fisher Scientific, Karlsruhe, Germany) for $30 \mathrm{~min}$, the cells were measured with a FACScan flow cytometer (BD Biosciences, Heidelberg, Germany).

Intracellular ROS levels were measured with $2^{\prime}, 7^{\prime}$-dichloro-dihydro-fluorescein diacetate (DCFH-DA). Briefly, $3 \times 10^{5}$ HDMECs seeded in 6-well plates were pretreated for $2 \mathrm{~h}$ with $0.5 \mathrm{mM}$ reducing agent dithiothreitol (DTT) and then exposed for $24 \mathrm{~h}$ to 0 or $2 \mathrm{mM}$ linalool. Then, the cells were incubated with $0.5 \mu \mathrm{M}$ DCFHDA (Sigma-Aldrich) at $37{ }^{\circ} \mathrm{C}$ for $30 \mathrm{~min}$. Alternatively, HDMECs were pretreated for $2 \mathrm{~h}$ with $0.5 \mathrm{mM}$ DTT, incubated for $30 \mathrm{~min}$ with $0.5 \mu \mathrm{M}$ DCFH-DA and then treated for 30 min with $0.5 \mathrm{mM} \mathrm{H}_{2} \mathrm{O}_{2}$. After collecting the cells with a scraper, the intracellular fluorescence intensity was then measured by a FACScan flow cytometer (BD Biosciences). $\mathrm{H}_{2} \mathrm{O}_{2}$-treated cells served as a positive control for ROS generation.

To evaluate the activation of $\beta 1$ integrin, $3 \times 10^{5}$ HDMECs seeded in 6-well plates were pretreated for $2 \mathrm{~h}$ with or without $5 \mu \mathrm{M} \mathrm{N}$-(3-aminopropyl)-2-[(3-methylphenyl) methoxy]- $N$-(2-thienylmethyl)-benzamide hydrochloride (AMTB, Sigma-Aldrich), a specific TRPM8 inhibitor. Then, the cells were exposed to $2 \mathrm{mM}$ DMSO or linalool for 30 min, followed by rinse with HEPES buffer supplemented with $1 \mathrm{mM} \mathrm{Mn}^{2+}$ and incubation with PE-conjugated anti- $\beta 1$ integrin antibody (clone HUTS-21; 1:20; BD Pharmingen, Heidelberg, Germany) at $37{ }^{\circ} \mathrm{C}$ for $30 \mathrm{~min}$. After collection with a cell scraper, the cells were measured with a FACScan flow cytometer (BD Biosciences).

\section{Migration assay}

EC migration was analyzed by two different assays. For the scratch wound healing assay, $3.2 \times 10^{5}$ HDMECs were seeded in $35-\mathrm{mm}$ dishes and then exposed to different concentrations of linalool. After $24 \mathrm{~h}$ of incubation, four scratches were generated onto the cell monolayer using a $10 \mu \mathrm{L}$ pipette tip. Immediately after scratching $(0 \mathrm{~h})$ and after $6 \mathrm{~h}$, images of the scratches were taken using a phasecontrast microscope (Leica DFC450C; Leica Microsystems, Wetzlar, Germany). Wound areas were measured using the LAS V4.8 software (Leica Microsystems).

For the transwell migration assay, HDMECs were seeded in $100-\mathrm{mm}$ dishes and then exposed for $24 \mathrm{~h}$ to different concentrations of linalool. Thereafter, $2.5 \times 10^{5}$ HDMECs treated with linalool or vehicle were suspended in $500 \mu \mathrm{L}$ endothelial basal medium (EBM) without supplements and seeded into the inserts of 24 -transwell plates ( $8 \mu \mathrm{m}$ pores; Corning, Wiesbaden, Germany), while $750 \mu \mathrm{L}$ EBM containing $1 \%$ fetal calf serum (FCS) was added to the bottom chamber. After $5 \mathrm{~h}$ of incubation, the non-migrated cells were removed and the migrated cells were stained with Diff-Quick (LT-SYS, Berlin, Germany) and counted under a BZ-8000 microscope (Keyence, Osaka, Japan).

\section{Tube formation assay}

To assess the tube-forming activity of ECs, $1.7 \times 10^{4}$ HDMECs were seeded into each well of 96 -well plates precoated with $50 \mu \mathrm{L}$ Matrigel (Corning) and then treated with different concentrations of linalool. After $24 \mathrm{~h}$, the newly formed vessel-like structures were observed under a phasecontrast microscope (BZ-8000; Keyence) and analyzed by quantifying the number of meshes using ImageJ software with the angiogenesis analyzer plug-in [U.S. National Institutes of Health (NIH), Bethesda, Maryland, USA].

\section{Spheroid sprouting assay}

As previously described [19], 500 HDMECs suspended in EGM-MV containing 20\% methylcellulose (w/v) (Thermo Fisher Scientific) were seeded into each well of non-adherent round bottom 96-well plates. After $24 \mathrm{~h}$ of incubation, spheroids were collected and suspended in a collagen solution mixed with EBM containing 20\% FCS and $0.5 \%$ methylcellulose (w/v) at a ratio of 1:2. This collagen solution consists of 8 volumes rat acidic collagen extract (Serva, Heidelberg, Germany), 1 volume $10 \times$ Medium 199 (Sigma-Aldrich) and 1 volume $0.2 \mathrm{M} \mathrm{NaOH}$. Then, the spheroid mixture was rapidly transferred into a pre-warmed 24-well plate. After incubation for $45 \mathrm{~min}$, EGM-MV containing different concentrations of linalool was gently added onto the spheroids. The spheroids were photographed after $24 \mathrm{~h}$ of incubation by a phase-contrast microscope (Leica DFC450C) and the cumulative length of the sprouts that had grown out of each spheroid was measured using the LAS V4.8 software (Leica Microsystems).

\section{Aortic ring assay}

As previously described [20], aortic rings from Wistar albino Glaxo rats were embedded in $200 \mu \mathrm{L}$ Matrigel (Corning) in each well of 48-well plates. After incubation for 15 min allowing for Matrigel polymerization, $800 \mu \mathrm{L}$ Dulbecco's modified Eagle's medium (DMEM) containing 10\% FCS, penicillin, streptomycin and different concentrations of linalool was added. After 6 days with a medium change 
on day 3, the aortic rings were photographed by a phasecontrast microscope (BZ-8000; Keyence) and the area of vascular sprouting from the aortic rings was measured using the image analysis application software (Keyence).

\section{In vivo Matrigel plug assay}

The in vivo effects of linalool on angiogenesis were evaluated in a Matrigel plug assay. Briefly, $200 \mu \mathrm{L}$ growth factorreduced Matrigel (Corning) containing $30 \mathrm{IU} / \mathrm{mL}$ heparin (Braun, Melsungen, Germany), $1 \mu \mathrm{g} / \mathrm{mL}$ VEGF (PAN Biotech, Bayern, Germany) and $2 \mathrm{mM}$ DMSO or linalool was injected subcutaneously into 5-7-month-old male BALB/c mice. After 7 days, the Matrigel plugs were excised for immunohistochemical analyses. This experiment was approved by the Local Animal Protection Committee and was conducted according to the German legislation for animal welfare and the Guide for the Care and Use of Laboratory Animals (8th Edition, 2011).

\section{Immunohistochemistry}

For the detection of microvessels within the Matrigel plugs, sections were cut and stained with a rat anti-mouse CD31 antibody (1:100; Dianova, Hamburg, Germany) followed by a goat-anti-rat Alexa Fluor 555-labeled secondary antibody (1:100; Life Technologies). Cell nuclei were visualized by staining with Hoechst 33342 (Sigma-Aldrich). Sections were then analyzed using a fluorescence microscope (BZ-8000; Keyence) and the microvessel density was determined by counting the number of CD31-positive microvessels in 6 microscopic regions of interest (ROIs) of each plug.

\section{Western blot analysis}

Treated HDMECs were lysed with lysis buffer composed of $10 \mathrm{mM}$ Tris ( $\mathrm{pH} 7.5), 10 \mathrm{mM} \mathrm{NaCl}, 0.1 \mathrm{mM}$ EDTA, $0.5 \%$ Triton-X $100,0.02 \% \mathrm{NaN}_{3}$, phenylmethylsulfonyl fluoride $(1: 500 \mathrm{v} / \mathrm{v})$, protease inhibitor cocktail (1:100 v/v; Sigma-Aldrich) and phosphatase inhibitor cocktail $(1: 100 \mathrm{v} / \mathrm{v}$; Sigma-Aldrich) for $10 \mathrm{~min}$ on ice. The cell lysate was then transferred to tubes and centrifuged at 4 ${ }^{\circ} \mathrm{C}$ for $30 \mathrm{~min}$ at $13,000 \times \mathrm{g}$. The supernatant was collected and protein concentrations were measured using the Pierce BCA Protein Assay (Thermo Fisher Scientific) with BSA as a standard. Subsequently, $10 \mu \mathrm{g}$ proteins per lane were separated on $10 \%$ sodium dodecyl sulfate (SDS) polyacrylamide gels and transferred to a polyvinylidene difluoride (PVDF) membrane (BioRad, Munich, Germany). The membrane was then blocked with Blotting-Grade Blocker (BioRad) and incubated with a rabbit monoclonal anti-pAKT1/2/3 antibody (1:100; Cell Signaling Technology), a rabbit monoclonal anti-AKT antibody
(1:500; Cell Signaling Technology), a mouse monoclonal anti-pERK antibody (1:300; Abcam, Cambridge, UK), a rabbit polyclonal anti-ERK antibody (1:300; Abcam), a rabbit monoclonal anti-focal adhesion kinase (FAK) antibody (1:100; Cell Signaling Technology), a rabbit monoclonal anti-pFAK antibody (1:250; Cell Signaling Technology), a rabbit monoclonal anti-TRPM8 antibody (1:25; Abcam), a mouse monoclonal anti-bone morphogenetic protein (BMP)-2 antibody (1:30; Proteintech, Manchester, UK), a rabbit polyclonal anti-cyclin-dependent kinase (CDK) 4 antibody (1:10; Santa Cruz Biotechnology, Texas, USA), a rabbit polyclonal anti-CDK6 antibody (1:30; Santa Cruz Biotechnology), a rabbit monoclonal anti-CDK9 antibody (1:150; Cell Signaling Technology), a rabbit polyclonal anti-cyclooxygenase (COX)-2 antibody (1:50; Abcam), a mouse monoclonal anti-endothelial nitric oxide synthase (eNOS) antibody (1:100; BD Bioscience), a mouse monoclonal anti-intercellular adhesion molecule (ICAM)-1 antibody (1:30; Santa Cruz Biotechnology), a mouse monoclonal anti-p21 antibody (1:250; Abcam), a mouse monoclonal anti-Ras homolog family member A (RhoA) antibody (1:250; Cell Signalling Technology), a mouse monoclonal anti-sirtuin (SIRT) 1 antibody (1:100; Abcam), a rabbit polyclonal anti-VEGFA antibody (1:50; Abcam) or a mouse monoclonal anti- $\beta$-actin antibody (1:5000; Sigma-Aldrich), followed by an anti-mouse (1:1500; Dako/Agilent, Hamburg, Germany) or anti-rabbit secondary antibody conjugated to horseradish peroxidase (HRP) (1:1000; R\&D, Abingdon, UK). Protein signals were detected with an enhanced chemiluminescence (ECL) kit (GE Healthcare, Freiburg, Germany) under a Chemocam device (Intas, Göttingen, Germany) and the band intensities were analyzed using ImageJ software (NIH).

\section{Intracellular ATP measurement}

The intracellular ATP level was measured using an ATP Determination Kit (Thermo Fisher Scientific) according to the manufacturer's instructions. Briefly, HDMECs were exposed to $2 \mathrm{mM}$ DMSO or linalool in the presence or absence of $5 \mu \mathrm{M}$ AMTB (Sigma-Aldrich) or $1 \mu \mathrm{M}$ PD0325901, which specifically inhibits MEK/ERK signaling (Selleckchem, Munich, Germany). After $24 \mathrm{~h}$ of incubation, the cells were rinsed with phosphate-buffered saline (PBS) and lysed with lysis buffer (Promega, Walldorf, Germany) for $15 \mathrm{~min}$ at room temperature by shaking. The cell lysate was then centrifuged with full speed for $5 \mathrm{~min}$. The supernatant was collected and mixed with standard reaction solution consisting of reaction buffer, 0.1 M DTT, $10 \mathrm{mM}$ D-luciferin and firefly luciferase. Luminescence was measured using a Tecan Infinite M200 Pro luminometer (Männedorf, Switzerland). 


\section{$\mathrm{Ca}^{2+}$ transient acquisition and analysis}

$\mathrm{Ca}^{2+}$ measurements in living ECs were conducted as previously described [21]. Briefly, $1 \times 10^{5}$ HDMECs were seeded on a coverslip in each well of 12-well plates and treated for $2 \mathrm{~h}$ with $5 \mu \mathrm{M}$ AMTB, $1 \mu \mathrm{M}$ PD0325901 or $2.5 \mu \mathrm{M}$ BAPTA-AM (Abcam), which is a specific $\mathrm{Ca}^{2+}$ chelator. After loading with Fluo-4 AM (Life Technologies), cells were bathed in Tyrode's solution $(135 \mathrm{mM} \mathrm{NaCl}, 5.4 \mathrm{mM}$ $\mathrm{KCl}, 1.8 \mathrm{mM} \mathrm{CaCl}_{2}, 10 \mathrm{mM}$ glucose, $2 \mathrm{mM} \mathrm{MgCl}_{2}$ and 10 mM HEPES; $\mathrm{pH} 7.35$ ) at $26^{\circ} \mathrm{C}$ and mounted on an inverted microscope (Eclipse TE, Nikon, Düsseldorf, Germany) with 20x oil-immersion objectives (Plan Fluor, $20 \times 0.75$, Nikon). Excitation was performed at the wavelength of $470 \mathrm{~nm}$ by LED (pE-100, CoolLED Ltd., Andover, USA) and the emission of Fluo-4 was detected by a COMS camera (Orca Flash 4.0; Hamamatsu, Japan) with imaging at 5 frames per second in a size of $512 \times 512$ pixels. Stimulation with chemical compounds at indicated concentrations was achieved by a local solenoid-controlled gravity-driven perfusion system. The acquired images were analyzed by ImageJ software to correct the image background and collect the fluorescence intensity in ROIs over time. The data were imported into IgorPro (Wavemetrics, Lake Oswego, USA) and processed as the self-ratio traces $\left(F / F_{0}\right)$, for which the fluorescence at any given time point $(F)$ was divided by the resting fluorescence $\left(F_{0}\right)$ to account for different dye loading. The amplitude of $\mathrm{Ca}^{2+}$ transient was calculated as the peak value of the self-ratio trace.

\section{Statistics}

Statistical analysis was performed using the SigmaPlot software (SigmaStat; Jandel Corporation, San Rafael, CA, USA). Differences between two groups were analyzed by the unpaired Student's $t$-test and differences between multiple groups were analyzed by one-way ANOVA followed by the Student-Newman-Keuls post hoc test including Bonferroni correction to compensate for multiple comparisons. All values were expressed as means \pm SEM. Statistical significance was accepted for $P$-values $<0.05$.

\section{Results}

\section{Action of linalool on HDMEC viability and proliferation}

We first investigated the effects of linalool on HDMEC viability and cytotoxicity by means of WST-1 and LDH assays, respectively. These assays showed that linalool concentrations of up to $2 \mathrm{mM}$ do not affect the viability of HDMECs (Fig. 1a) and do not exert any cytotoxic effects on these cells
(Fig. 1b). Accordingly, we chose non-cytotoxic concentrations between 0.25 and $2 \mathrm{mM}$ linalool for our in vitro and in vivo angiogenesis assays.

Next, we analyzed the effects of linalool on HDMEC proliferation. For this purpose, BrdU incorporated into cellular DNA during cell proliferation was detected by flow cytometry. We found that 1 and $2 \mathrm{mM}$ linalool causes a $15 \%$ and $23 \%$ reduction in HDMEC proliferation, respectively (Fig. 1c, d).

\section{Action of linalool on HDMEC migration}

To study the effects of linalool on the migratory activity of HDMECs, scratch wound healing and transwell migration assays were performed. Linalool significantly delayed the wound closure of scratched HDMEC monolayers (Fig. 2a, b) and dose-dependently reduced the number of migrated HDMECs (Fig. 2c, d).

\section{Action of linalool on HDMEC tube formation and spheroid sprouting}

We then analyzed the effects of linalool on the tube-forming capacity of HDMECs. Treatment with $2 \mathrm{mM}$ linalool significantly reduced the number of newly formed tube meshes in a tube formation assay (Fig. 3a, b).

Moreover, we demonstrated in a three-dimensional spheroid sprouting assay that linalool dose-dependently diminishes the cumulative length of sprouts growing out of HDMEC spheroids (Fig. 3c, d).

\section{Action of linalool on angiogenesis ex vivo and in vivo}

To confirm our in vitro findings, we performed an ex vivo aortic ring assay. In this assay, rat aortic rings embedded in Matrigel were incubated with different doses of linalool for 6 days. By this, we observed that 1 and $2 \mathrm{mM}$ linalool significantly decreases the area of sprouting from aortic rings when compared to vehicle-treated controls (Fig. 4a, b).

In addition, we evaluated the effects of linalool on angiogenesis in an in vivo Matrigel plug assay. Matrigel plugs containing $2 \mathrm{mM}$ linalool exhibited a 31\% lower microvessel density at day 7 after implantation into BALB/c mice when compared to controls (Fig. 4c, d).

\section{Action of linalool on AKT and ERK signaling}

To clarify the molecular mechanisms underlying the inhibitory action of linalool on angiogenesis, we first analyzed the activity of two pivotal angiogenic signaling pathways, i.e., PI3K/AKT/mTOR and Raf/MEK/ERK, in HDMECs exposed to different concentrations of linalool. Western blot 

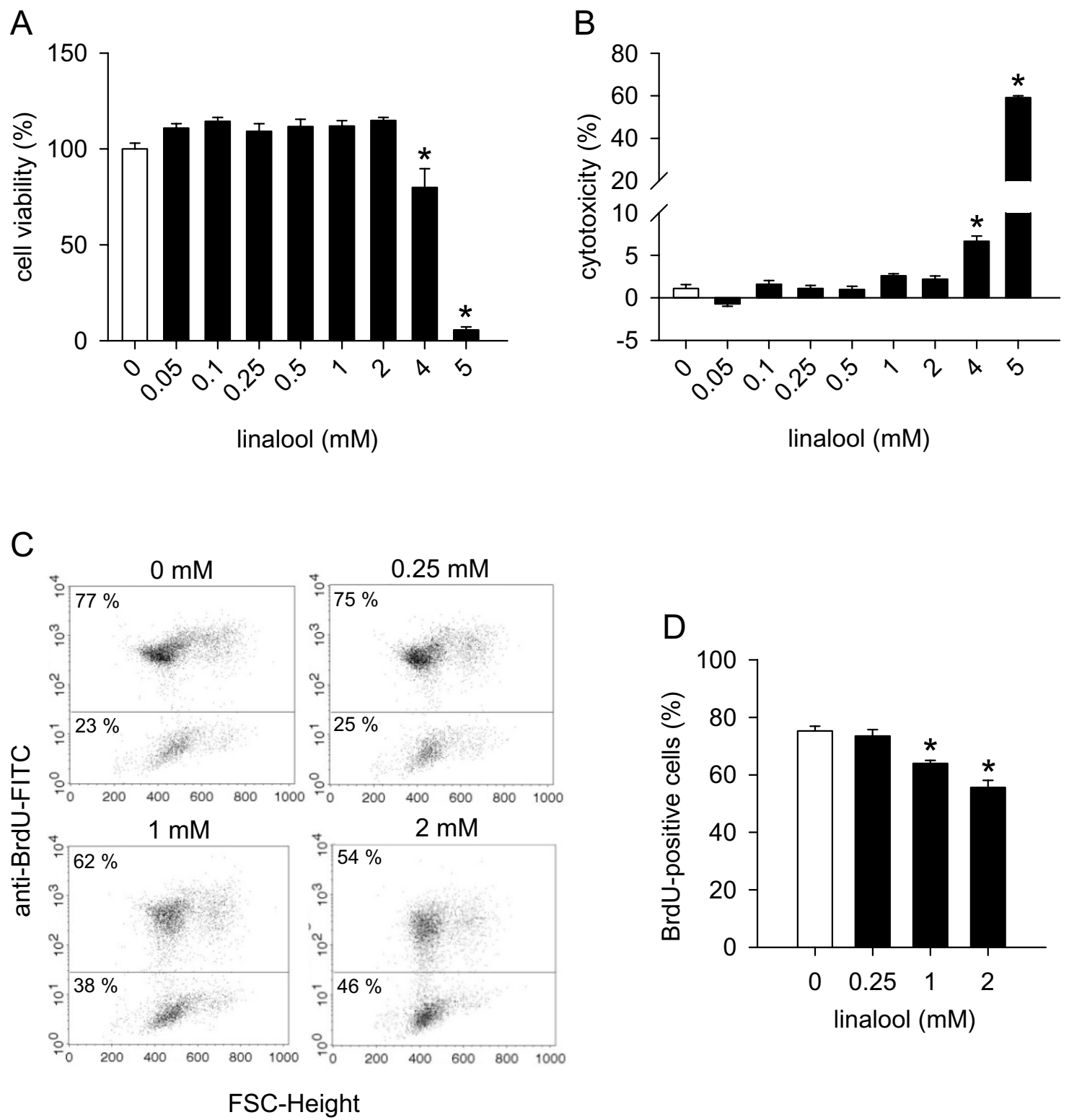

Fig. 1 Linalool inhibits HDMEC proliferation. a, b Viability (in \% of $0 \mathrm{mM}$ ) of HDMECs (a) and cytotoxicity (in \% of the total cell death) of linalool (b) as assessed by the WST-1 (a) and LDH assay (b), respectively. HDMECs were exposed for $24 \mathrm{~h}$ to serial dilutions $(0.05-5 \mathrm{mM})$ of linalool or vehicle $(0 \mathrm{mM})(n=4)$. c: Flow cytometry

analyses revealed that linalool strongly increases the phosphorylation of ERK without affecting AKT phosphorylation (Fig. 5a-c). Based on this result, we blocked the ERK pathway with PD0325901, a highly selective and non-ATPcompetitive MEK inhibitor. For this purpose, we used a concentration of $1 \mu \mathrm{M}$ PD0325901, which was non-cytotoxic in a WST-1 assay (Fig. S1a), but reduced the linalool-increased as well as the basal level of phosphorylated ERK (Fig. 5d, e). Of interest, the inhibition of ERK phosphorylation markedly counteracted linalool-suppressed HDMEC spheroid scatter plots of HDMECs that were exposed for $24 \mathrm{~h}$ to $0.25,1$ and $2 \mathrm{mM}$ linalool or vehicle $(0 \mathrm{mM})$, incorporated with $\mathrm{BrdU}$ and then stained with FITC-conjugated anti-BrdU antibody. d BrdU-positive cells (in $\%$ of the total cell number) of vehicle- or linalool-treated HDMECs $(n=3)$. Means \pm SEM. $* P<0.05$ vs. $0 \mathrm{mM}$

sprouting (Figs. 5f, S2a). To further confirm this finding, we downregulated the intracellular level of ERK by transfecting HDMECs with siRNAs (si-ERK). The transfection efficiency of si-ERK was assessed by western blot and is shown in Fig. 5g, h. As expected, downregulation of ERK significantly suppressed the sprouting of HDMEC spheroids (Figs. 5i, S2b). However, ERK knockdown counteracted linalool-suppressed spheroid sprouting (Figs. 5i, S2b). This indicates that linalool inhibits angiogenesis at least partially by promoting ERK phosphorylation. 

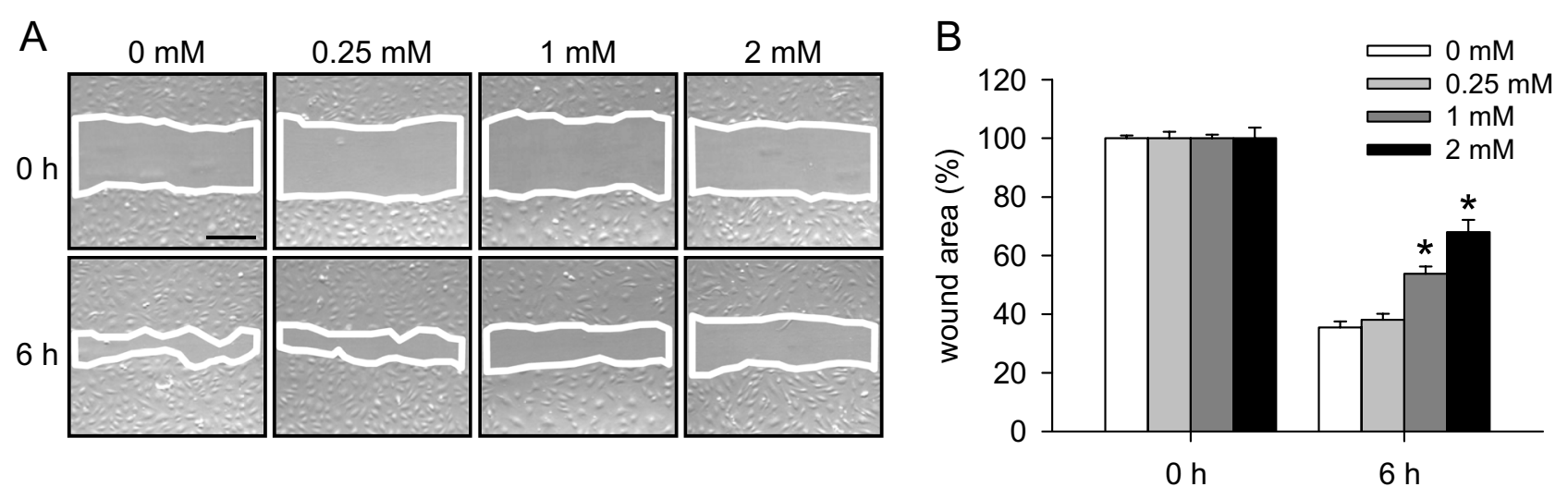

C
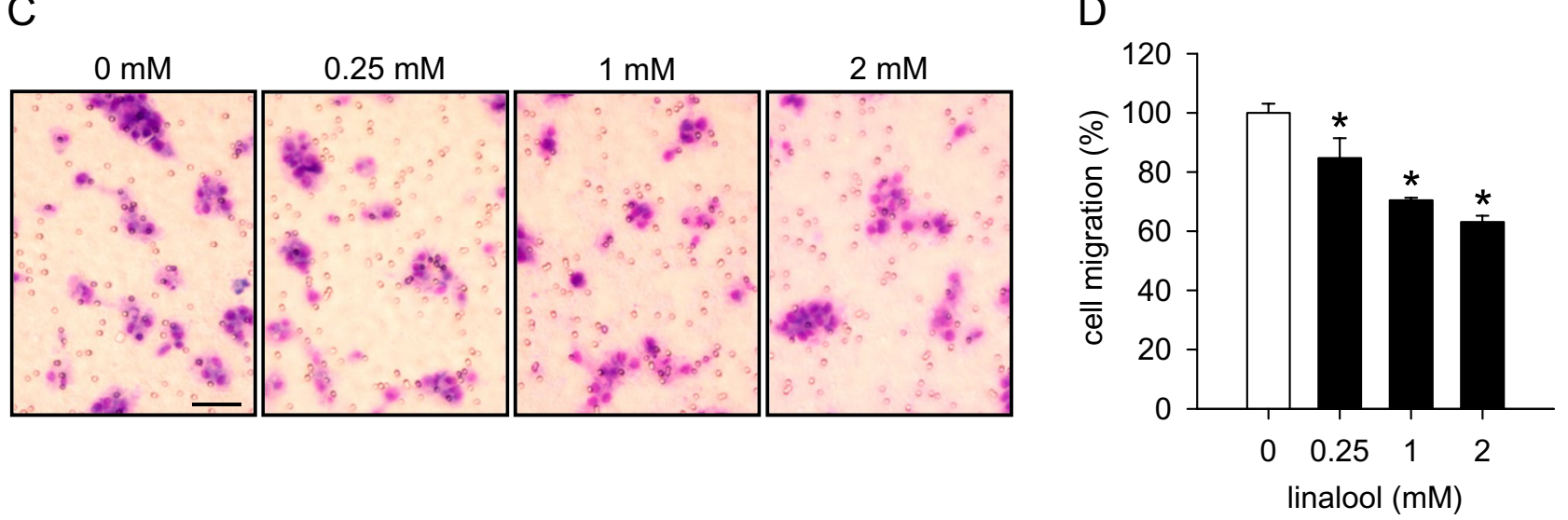

Fig. 2 Linalool inhibits HDMEC migration. a Phase-contrast microscopic images of HDMEC monolayers, which were scratched and then exposed for $6 \mathrm{~h}$ to $0.25,1$ and $2 \mathrm{mM}$ linalool or vehicle $(0$ $\mathrm{mM})$. Wound areas are marked with white lines. Scale bar $220 \mu \mathrm{m}$. b Wound area (in \% of $0 \mathrm{~h}$ ) of scratched HDMEC monolayers at 0 and $6 \mathrm{~h}$, as assessed by the scratch wound healing assay $(n=8)$. $\mathrm{c}$ Light

\section{Action of linalool on intracellular ROS levels}

Recent studies showed that linalool induces ROS formation in several types of tumor cells, including glioblastoma U87 and hepatocellular carcinoma HepG2 cells [22, 23]. Uncontrolled ROS formation has been reported to impair the activity of ECs [24]. Indeed, plenty of chemical compounds, such as thalidomide, magnolol and dextran-catechin, exert their anti-angiogenic effects by triggering ROS production [25-27]. Therefore, we assessed the effects of linalool on the intracellular ROS levels of ECs. By flow cytometry following DCFH-DA staining, we observed a significant increase of ROS production in linalool-treated HDMECs when compared to vehicle-treated controls (Fig. 6a). $\mathrm{H}_{2} \mathrm{O}_{2}$ was used as a positive control for ROS generation.

To further investigate whether ROS formation contributes to the inhibitory effect of linalool on angiogenesis, we utilized DTT, a wildly used reducing agent, to inhibit microscopic images of migrated HDMECs, which were treated for $24 \mathrm{~h}$ with $0.25,1$ and $2 \mathrm{mM}$ linalool or vehicle $(0 \mathrm{mM})$. Scale bar 70 $\mu \mathrm{m}$. d Migration (in \% of $0 \mathrm{mM}$ ) of HDMECs, which were treated with vehicle or linalool, as assessed by the transwell migration assay $(n=4)$. Means \pm SEM. ${ }^{*} P<0.05$ vs. $0 \mathrm{mM}$

the production of ROS. For this purpose, linalool-exposed HDMEC spheroids were treated with a concentration of 0.5 mM DTT, which was non-cytotoxic (Fig. S1c), but effectively suppressed linalool- and $\mathrm{H}_{2} \mathrm{O}_{2}$-induced ROS production (Fig. 6a). However, our data showed that DTT has no effects on linalool-suppressed HDMEC sprouting (Figs. 6b, S3a).

\section{Action of linalool on intracellular ATP levels}

A previous study reported that linalool decreases intracellular ATP levels and reduces the viability of HepG2 cells by inhibiting the mitochondrial complexes I and II [28]. Given the fact that ATP, the primary energy storage molecule, is essential for EC survival, proliferation and migration, we measured the intracellular ATP level of HDMECs by means of a luciferase assay. Treatment with $2 \mathrm{mM}$ linalool significantly reduced the intracellular ATP level by $28 \%$ when 
A

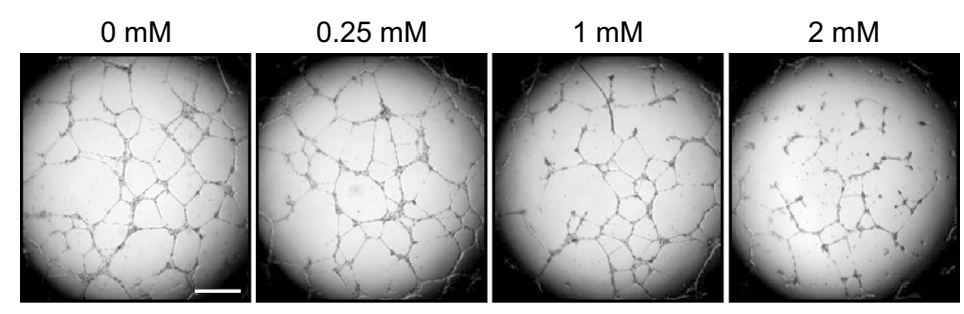

C

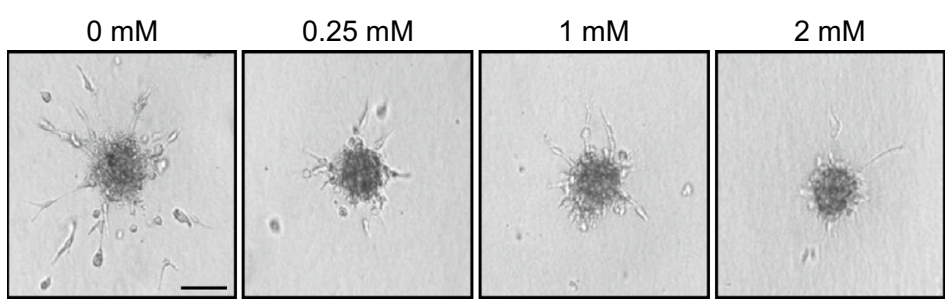

B

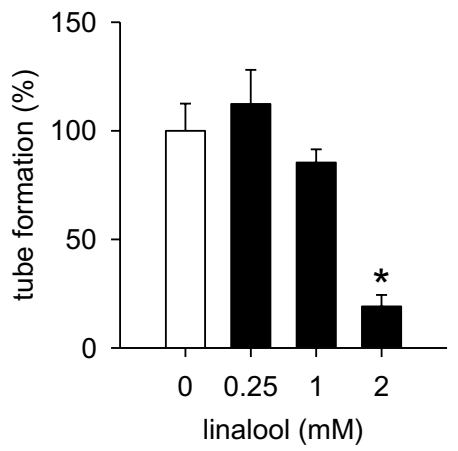

D

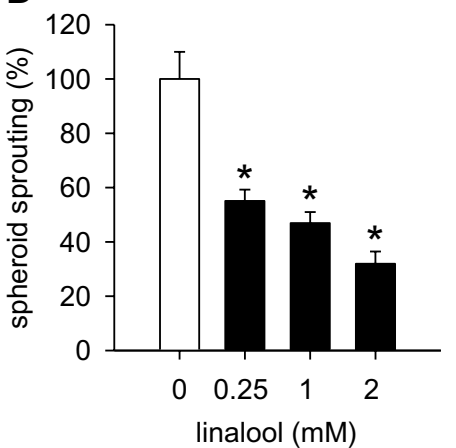

Fig. 3 Linalool suppresses HDMEC tube formation and spheroid sprouting. a Phase-contrast microscopic images of tube-forming HDMECs. The cells were exposed for $18 \mathrm{~h}$ to $0.25,1$ and $2 \mathrm{mM}$ linalool or vehicle $(0 \mathrm{mM})$. Scale bar $750 \mu \mathrm{m}$. b Tube formation (in $\%$ of $0 \mathrm{mM}$ ) of HDMECs, which were treated with vehicle or linalool, as assessed by the tube formation assay $(n=4)$. c Phase-contrast micro-

compared to vehicle-treated controls (Fig. 6c). Based on these findings, we added exogenous ATP to HDMEC spheroids. This efficiently rescued the inhibition of HDMEC spheroid sprouting induced by linalool (Figs. 6d, S3b), indicating that linalool inhibits angiogenesis at least partially through decreasing intracellular ATP levels.

\section{Action of linalool on TRPM8 activity}

Linalool was identified by Behrendt et al. as an agonist of TRPM8 [29]. This calcium-permeable cation channel has recently been shown to inhibit EC adhesion, migration and tube formation [8]. Therefore, we analyzed the activity of TRPM8 in linalool-treated HDMECs by measuring the intracellular calcium concentration. Menthol, a well-known TRPM8 agonist, highly stimulated the influx of $\mathrm{Ca}^{2+}$ into HDMECs (Fig. 6e, f). Similarly, linalool markedly increased intracellular $\mathrm{Ca}^{2+}$ concentrations (Fig. 6e, f). To further investigate whether linalool evokes $\mathrm{Ca}^{2+}$ influx through activating TRPM8, we utilized the specific TRPM8 inhibitor AMTB. By means of a WST-1 assay, we observed that $10-100 \mu \mathrm{M}$ AMTB significantly reduces HDMEC viability (Fig. S1b). scopic images of HDMEC spheroids, which were treated for $24 \mathrm{~h}$ with $0.25,1$ and $2 \mathrm{mM}$ linalool or vehicle $(0 \mathrm{mM})$. Scale bar $90 \mu \mathrm{m}$. d Sprouting (in $\%$ of $0 \mathrm{mM}$ ) of HDMEC spheroids, which were treated with vehicle or linalool, as assessed by the spheroid sprouting assay $(n=15)$. Means \pm SEM. $* P<0.05$ vs. $0 \mathrm{mM}$

Accordingly, we chose a non-cytotoxic concentration of $5 \mu \mathrm{M}$ AMTB for the following assays. As expected, inhibition of TRPM8 with AMTB completely blocked the menthol-stimulated $\mathrm{Ca}^{2+}$ influx (Fig. 6e, f). Likewise, AMTB also totally reversed the increased intracellular $\mathrm{Ca}^{2+}$ concentration in linalool-treated HDMECs (Fig. 6e, f), indicating that linalool activates TRPM8 in these cells.

To analyze whether activated TRPM8 mediates the antiangiogenic activity of linalool, the specific TRPM8 inhibitor AMTB and siRNAs against TRPM8 (si-TRPM8) were exploited in the spheroid sprouting assays. The transfection efficiency of si-TRPM8 is evaluated in Fig. 6h, i. Consistently, both TRPM8 inhibition and knockdown completely reversed linalool-reduced HDMEC spheroid sprouting (Figs. 6g, j, S3c, d), indicating that linalool downregulates angiogenesis at least in part through activating TRPM8.

\section{Relation between ERK phosphorylation, intracellular ATP reduction and TRPM8 activation}

The findings above demonstrate that linalool inhibits angiogenesis through upregulating the phosphorylation 
A
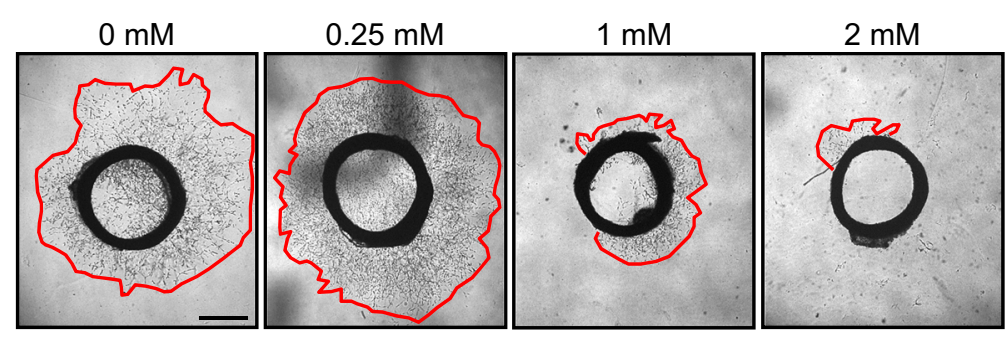

B

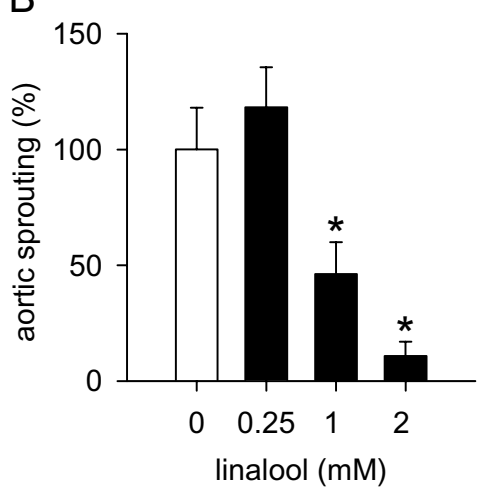

C
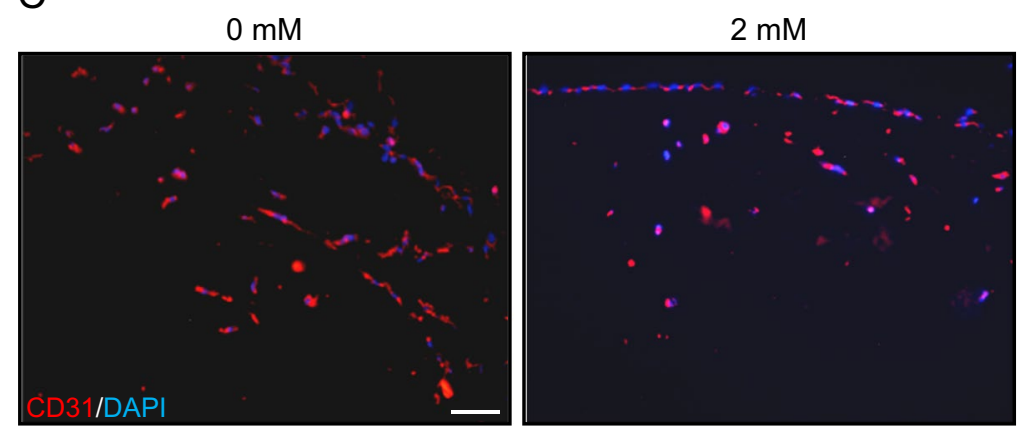

D

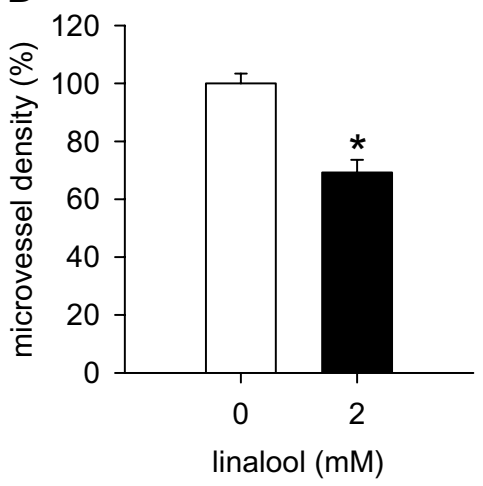

Fig. 4 Linalool inhibits angiogenesis ex vivo and in vivo. a Phasecontrast microscopic images of rat aortic rings, which were embedded in Matrigel and then exposed to $0.25,1$ and $2 \mathrm{mM}$ linalool or vehicle $(0 \mathrm{mM})$ for 6 days. Scale bar $750 \mu \mathrm{m}$. b Sprouting (in \% of $0 \mathrm{mM}$ ) of rat aortic rings, which were treated with vehicle or linalool, as assessed by the aortic ring assay $(n=11)$. c Fluorescence

of ERK, reducing intracellular ATP levels and activating TRPM8. To determine the relation between these three mechanisms, we assessed the phosphorylation of ERK in HDMECs that were pretreated with AMTB or ATP and then exposed to linalool. Western blot analyses showed that the pretreatment with ATP, but not with AMTB, completely reversed linalool-induced ERK phosphorylation (Fig. 7a, b). This result suggests that the linalool-increased ERK phosphorylation is caused by the decreased intracellular ATP levels, independently of TRPM8 activation.

Furthermore, we checked the intracellular ATP levels of HDMECs treated with linalool alone or in combination with AMTB or PD0325901. Luciferase assays showed that neither AMTB nor PD0325901 affects the reduction of intracellular ATP levels induced by linalool (Fig. 7c). These data confirm that intracellular ATP reduction locates upstream of ERK phosphorylation and also indicate that linalool-induced intracellular ATP reduction is independent of TRPM8 activation. microscopic images of sections from Matrigel plugs containing 0 or $2 \mathrm{mM}$ linalool. The sections were stained with anti-mouse CD31 antibody (red) and Hoechst 33342 (blue) to visualize ECs and cell nuclei, respectively. Scale bar $45 \mu \mathrm{m}$. d Microvessel density (in \% of $0 \mathrm{mM}$ ) of Matrigel plugs containing 0 or $2 \mathrm{mM}$ linalool, as assessed by immunohistochemistry $(n=9)$. Means \pm SEM. $* P<0.05$ vs. $0 \mathrm{mM}$

In addition, we assessed the activity of TRPM8 in HDMECs that were pretreated with PD0325901 and then exposed to linalool. Intracellular $\mathrm{Ca}^{2+}$ measurements revealed that PD0325901 has no effect on linalool-stimulated $\mathrm{Ca}^{2+}$ influx (Fig. 7d, e). This demonstrates that linalool activates TRPM8 independently of ERK phosphorylation.

\section{Downstream anti-angiogenic mediators of linalool- induced ERK phosphorylation}

It has been reported that phosphorylated ERK translocates into the nucleus and regulates hundreds of substrates, many of which participate in key physiological processes, such as cell proliferation, migration, survival and death [30]. To identify the downstream effectors of ERK that contribute to the anti-angiogenic effects of linalool, we analyzed the expression of 11 proteins, which are crucially involved in angiogenesis, in vehicle- and linalool-treated HDMECs by western blot. These proteins included BMP-2, CDK4, 


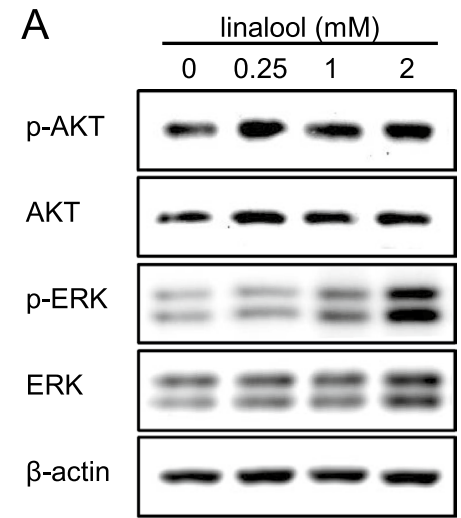

D

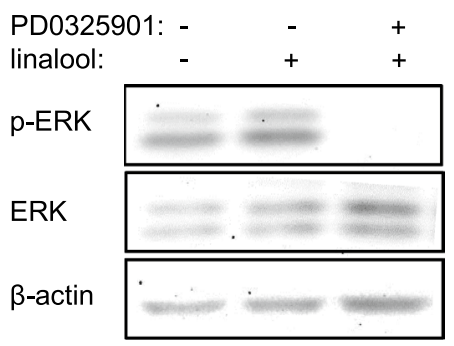

G

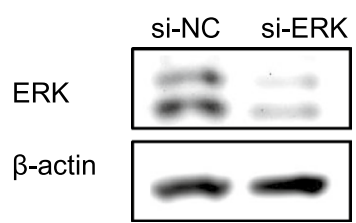

B

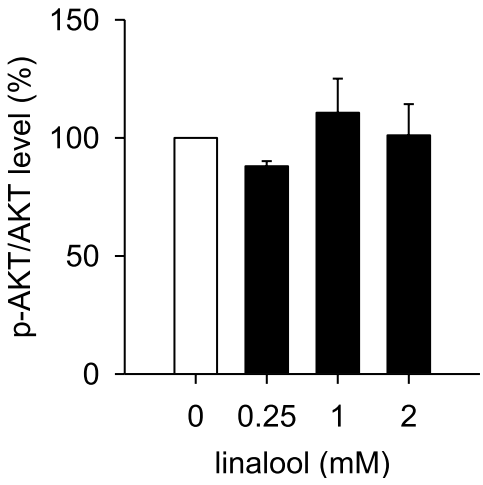

E

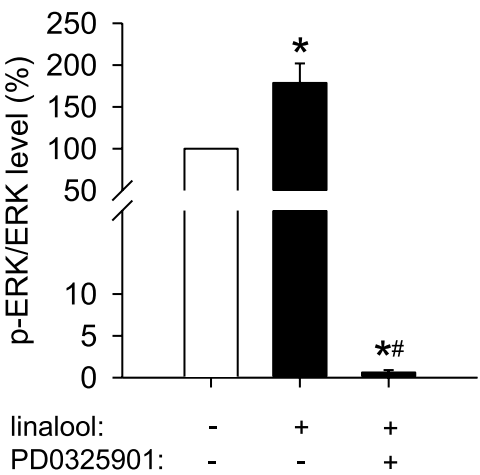

$\mathrm{H}$

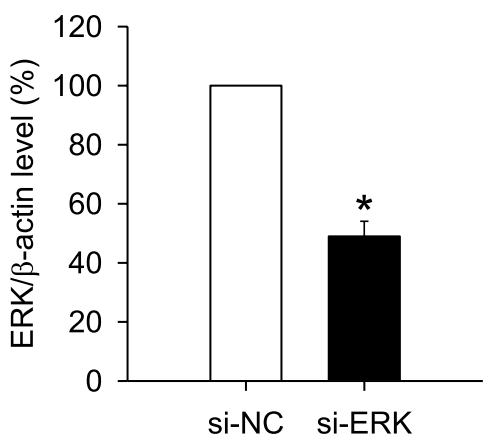

C

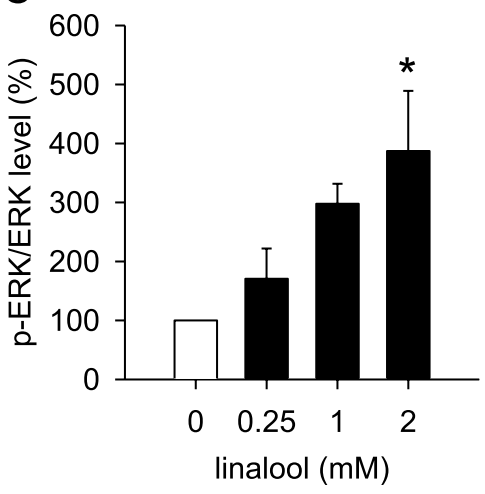

$\mathrm{F}$

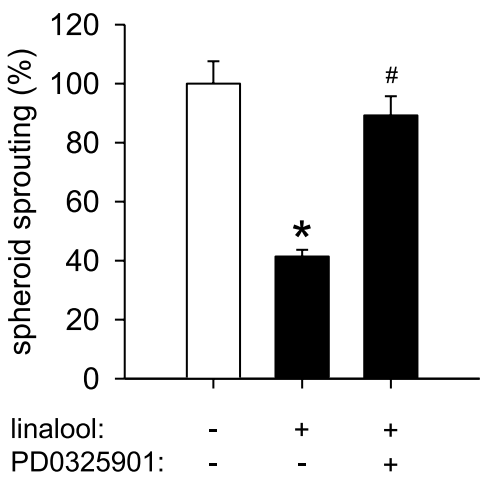

1

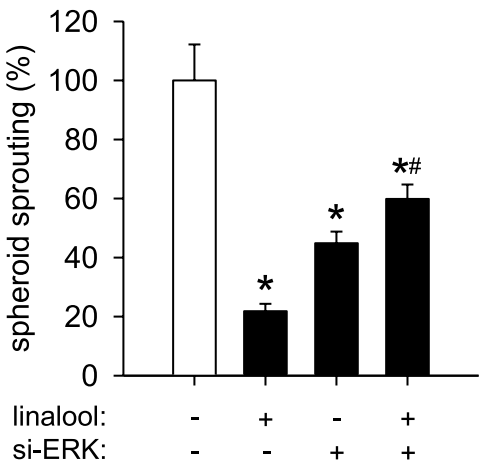

Fig. 5 Linalool inhibits angiogenesis through activation of ERK. a Western blot of p-AKT, AKT, p-ERK, ERK and $\beta$-actin expression in HDMECs, which were exposed for $30 \mathrm{~min}$ to $0.25,1$ and $2 \mathrm{mM}$ linalool or vehicle $(0 \mathrm{mM})$. b, c Expression levels of pAKT/AKT (b) and pERK/ERK (c) (in \% of $0 \mathrm{mM}$ linalool) as assessed by western blot ( $n=3$ independent experiments). d Western blot of p-ERK, ERK and $\beta$-actin expression in HDMECs, which were pretreated for $2 \mathrm{~h}$ with or without $1 \mu \mathrm{M}$ PD0325901, a specific MEK inhibitor, and then exposed for $30 \mathrm{~min}$ to 0 or $2 \mathrm{mM}$ linalool. e Expression levels of pERK/ERK (in \% of $0 \mathrm{mM}$ linalool) as assessed by western blot ( $n=4$ independent experiments). $\mathbf{f}$ Sprouting (in $\%$ of $0 \mathrm{mM}$ linalool) of HDMEC spheroids, which were treated for $24 \mathrm{~h}$ with 0 or $2 \mathrm{mM}$ linalool in the presence or absence of $1 \mu \mathrm{M}$ PD0325901, as assessed by the spheroid sprouting assay $(n=10)$. $\mathbf{g}$ Western blot of ERK and $\beta$-actin expression in HDMECs, which were transfected for $48 \mathrm{~h}$ with $20 \mathrm{nM}$ si-NC or si-ERK. h Expression levels of ERK/ $\beta$-actin (in \% of si-NC) as assessed by western blot ( $n=3$ independent experiments). i Sprouting (in $\%$ of $0 \mathrm{mM}$ linalool) of HDMEC spheroids consisting of si-NC- or si-ERK-transfected cells, which were treated for $24 \mathrm{~h}$ with 0 or $2 \mathrm{mM}$ linalool, as assessed by the spheroid sprouting assay $(n=10)$. Means \pm SEM. $* P<0.05$ vs. $0 \mathrm{mM}$ linalool or si-NC. ${ }^{\#} P<0.05$ vs. $2 \mathrm{mM}$ linalool 
CDK6, CDK9, COX-2, eNOS, ICAM-1, p21, RhoA, SIRT1 and VEGFA. Among them, the expression levels of eNOS and BMP-2 were significantly downregulated by linalool, while COX-2 was upregulated in linalool-treated HDMECs (Fig. S4a, b). To further determine whether linalool inhibits eNOS and BMP-2 expression through activating ERK, we examined the expression levels of the two proteins in HDMECs that were treated with vehicle or linalool in the presence or absence of PD0325901. Western blot analyses showed that the linalool-induced downregulation of BMP2, but not eNOS, is completely reversed by ERK inhibition (Fig. 8a-c). These findings indicate that linalool-induced ERK phosphorylation causes BMP-2 downregulation, which mediates the anti-angiogenic effect of linalool.

\section{Downstream anti-angiogenic mediators of linalool- induced TRPM8 activation}

Our above findings showed that linalool induces TRPM8 activation and consequently triggers $\mathrm{Ca}^{2+}$ influx. To investigate whether the anti-angiogenic effect of linalool is dependent on TRPM8-mediated calcium signaling, the selective $\mathrm{Ca}^{2+}$ chelator BAPTA-AM was used in the spheroid sprouting assay. For this purpose, linalool-exposed HDMEC spheroids were treated with a concentration of $2.5 \mu \mathrm{M}$ BAPTAAM, which was non-cytotoxic (Fig. S1d), but completely inhibited linalool-induced $\mathrm{Ca}^{2+}$ influx (Fig. 8d, e). By this, we could demonstrate that BAPTA-AM does not affect linalool-suppressed spheroid sprouting (Fig. 8f). This indicates that linalool inhibits angiogenesis independently of the pore function of TRPM8.

Genova et al. reported that TRPM8 inhibits EC adhesion through inactivation of $\beta 1$ integrin/FAK signaling [8]. We therefore analyzed $\beta 1$ integrin activity and FAK phosphorylation in HDMECs that were treated with vehicle or linalool in the presence or absence of AMTB by flow cytometry and western blot, respectively. We found that treatment with linalool causes a $34 \%$ decrease in $\beta 1$ integrin activity and a 30\% reduction in FAK phosphorylation, which could be totally reversed by TRPM 8 blockade (Fig. $8 \mathrm{~g}-\mathrm{i}$ ). These findings indicate that linalool-induced TRPM8 activation inhibits $\beta 1$ integrin/FAK signaling, which may explain the anti-angiogenic effect of linalool.

\section{Discussion}

Linalool is a naturally occurring monoterpene alcohol commonly found as a major component of essential oils from many aromatic plants. There are two enantiomers of linalool, i.e., (3S)-(+)-linalool and (3R)-(-)-linalool, which differ in their distribution in plant species, fragrance and biological properties [31]. The subject of this study was
$(3 R)-(-)$-linalool, because this enantiomer is more common in nature [15]. Given the fact that in many studies the enantiomeric identity of linalool is not specified, we herein use the term 'linalool' for both enantiomers.

Linalool possesses a broad spectrum of biological activities. An increasing number of studies reported anticancer effects of this phytochemical in vitro and in vivo. This action of linalool has been mainly attributed to its anti-proliferative and cytotoxic effects on different types of tumor cells through the generation of oxidative stress, induction of cell cycle arrest and suppression of the epithelial-mesenchymal transition (EMT) process [32-36]. In contrast, the effects of linalool on angiogenesis, which is essential for tumor growth and metastasis, remain elusive. In the present study, we now demonstrate a potent inhibitory effect of linalool on the angiogenic activity of ECs, which may markedly contribute to the anticancer activity of the compound.

Angiogenesis is a complex multi-step process, which includes EC proliferation, migration and tube formation [37]. To investigate which steps of this process are affected by linalool treatment, we performed a panel of in vitro angiogenesis assays. We found that linalool exerts pleiotropic anti-angiogenic effects on HDMECs, including the inhibition of HDMEC proliferation, migration, tube formation and spheroid sprouting. For this purpose, we used rather high linalool doses of 1 and $2 \mathrm{mM}$, which, however, did not affect the viability of the cells. In this context, it should be considered that linalool exhibits a poor solubility in culture medium and a low in vivo bioavailability. Accordingly, we used DMSO to increase the solubility of the compound in our in vitro assays.

In a next step, we investigated the effects of linalool on angiogenesis in an ex vivo rat aortic ring assay, which is based on the capacity of aortic rings to form new vessels in Matrigel, allowing the analysis of EC proliferation, migration, tube formation, microvessel branching and maturation [38]. Importantly, this assay closely mimics an in vivo environment. In fact, the angiogenic sprouting from aortic rings occurs in the presence of smooth muscle cells, pericytes, macrophages and fibroblasts [38]. In addition, the native ECs of aortic rings have not been modified by repeated passages and are quiescent at the time of explantation [39]. Accordingly, the aortic ring assay is widely used to evaluate the efficiency of pro- and anti-angiogenic compounds. In line with our HDMEC culture experiments, linalool significantly suppressed the vascular sprouting from rat aortic rings. Moreover, we found that linalool significantly reduces the microvessel density of Matrigel plugs 7 days after implantation into BALB/c mice when compared to controls. Notably, in this assay we analyzed the density of CD31-positive microvessels by means of immunohistochemistry. This parameter is more accurate compared to the measurement of plasma volume and hemoglobin mass in 
A

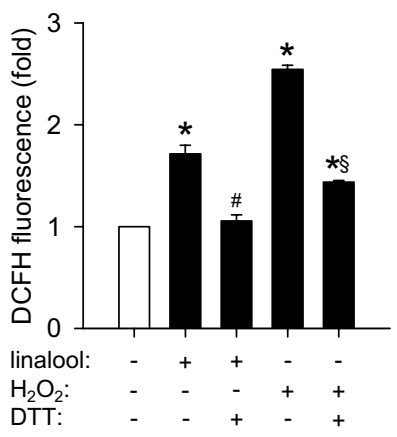

C

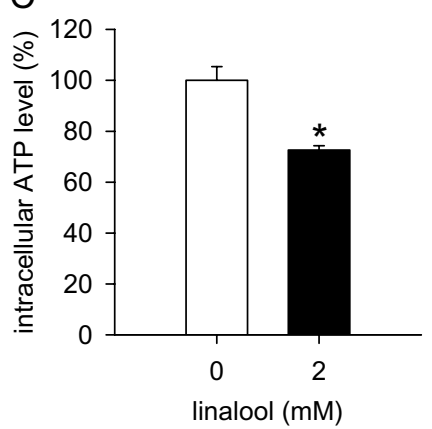

$\mathrm{B}$

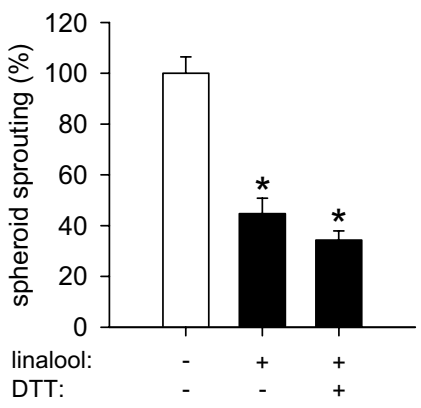

D

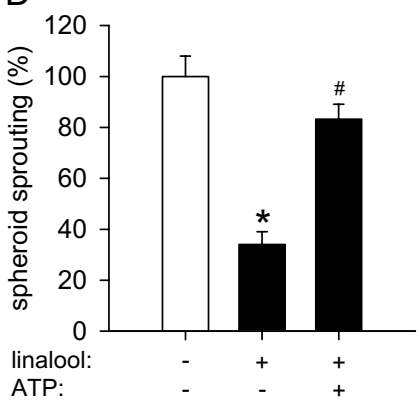

E

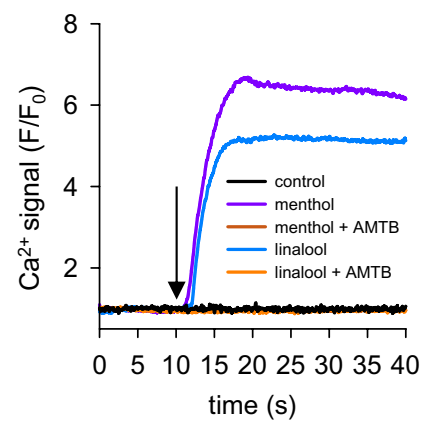

$\mathrm{H}$

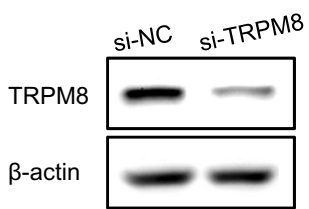

$\mathrm{F}$

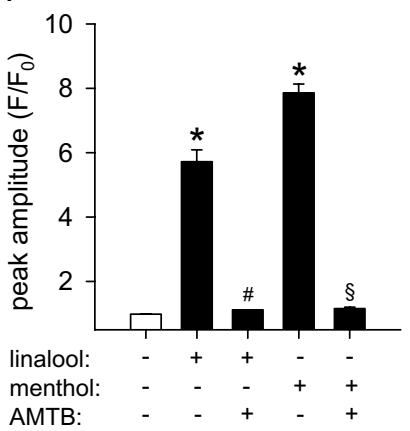

I

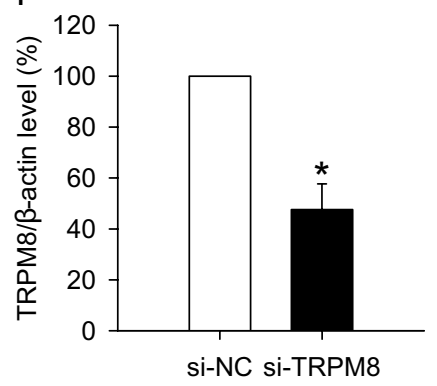

G

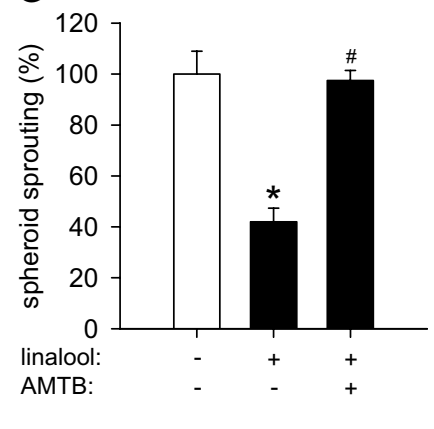

$\mathrm{J}$

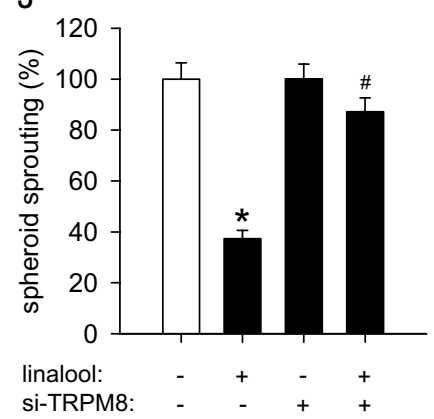

plugs, which crucially depends on the plug size [40]. Taken together, our findings demonstrate that linalool exhibits a potent anti-angiogenic activity, which is reproducible in several experimental in vitro and in vivo settings using ECs of different species.

To gain further insights into the mechanisms underlying the anti-angiogenic action of linalool, we examined the 
4Fig. 6 Linalool inhibits angiogenesis through reducing intracellular ATP and activating TRPM8. a DCFH fluorescence (in fold of 0 $\mathrm{mM}$ linalool) in HDMECs, which were pretreated with or without 0.5 $\mathrm{mM}$ DTT, a reducing agent, and then exposed to 0 or $2 \mathrm{mM}$ linalool for $24 \mathrm{~h}$ or $0.5 \mathrm{mM} \mathrm{H}_{2} \mathrm{O}_{2}$ for $30 \mathrm{~min}$, as assessed by flow cytometry ( $n=3$ independent experiments). b Sprouting (in \% of $0 \mathrm{mM}$ linalool) of HDMEC spheroids, which were treated for $24 \mathrm{~h}$ with 0 or $2 \mathrm{mM}$ linalool in the presence or absence of $0.5 \mathrm{mM}$ DTT, as assessed by the spheroid sprouting assay $(n=10)$. $\mathbf{c}$ Intracellular ATP level (in $\%$ of $0 \mathrm{mM}$ ) of HDMECs, which were treated for $24 \mathrm{~h}$ with 0 or $2 \mathrm{mM}$ linalool, as assessed by the luciferase assay $(n=4)$. d Sprouting (in $\%$ of $0 \mathrm{mM}$ linalool) of HDMEC spheroids, which were treated for $24 \mathrm{~h}$ with 0 or $2 \mathrm{mM}$ linalool in the presence or absence of $1 \mathrm{mM}$ ATP, as assessed by the spheroid sprouting assay $(n=10)$. e $\mathrm{Ca}^{2+}$ signal $\left(F / F_{0}\right)$ in HDMECs, which were pretreated with or without 5 $\mu \mathrm{M}$ AMTB (a specific TRPM8 blocker) for $2 \mathrm{~h}$, loaded with Fluo-4 $\mathrm{AM}$ and then stimulated with 0 or $2 \mathrm{mM}$ linalool or $1 \mathrm{mM}$ menthol. The onset of stimulation is indicated by a black arrow. f Peak amplitude $\left(F / F_{0}\right)$ of $\mathrm{Ca}^{2+}$ signal in HDMECs, which were pretreated with or without AMTB, loaded with Fluo-4 AM and then stimulated with vehicle, linalool or menthol. g Sprouting (in \% of $0 \mathrm{mM}$ linalool) of HDMEC spheroids, which were treated for $24 \mathrm{~h}$ with 0 or $2 \mathrm{mM}$ linalool in the presence or absence of $5 \mu \mathrm{M}$ AMTB, as assessed by the spheroid sprouting assay $(n=10)$. h Western blot of TRPM8 and $\beta$-actin expression in HDMECs, which were transfected for $48 \mathrm{~h}$ with $120 \mathrm{nM}$ si-NC or si-TRPM8. i Expression levels of TRPM8/ $\beta$-actin (in \% of si-NC) as assessed by western blot $(n=3$ independent experiments). $\mathbf{j}$ Sprouting (in $\%$ of $0 \mathrm{mM}$ linalool) of HDMEC spheroids consisting of si-NC- or si-TRPM8-transfected cells, which were treated for $24 \mathrm{~h}$ with 0 or $2 \mathrm{mM}$ linalool, as assessed by the spheroid sprouting assay $(n=10)$. Means \pm SEM. $* P<0.05$ vs. $0 \mathrm{mM}$ linalool or si-NC. ${ }^{\#} P<0.05$ vs. $2 \mathrm{mM}$ linalool. ${ }^{\S} P<0.05$ vs. $\mathrm{H}_{2} \mathrm{O}_{2}$ or menthol

effects of the compound on two key angiogenesis-related signaling pathways, i.e., PI3K/AKT/mTOR and Raf/MEK/ ERK. In contrast to previous studies reporting that linalool inhibits AKT/mTOR signaling in human oral cancer OECM 1 cells and hepatoma HepG2 cells [23, 41], we did not detect a suppression of AKT phosphorylation in linalool-treated HDMECs. This indicates that the compound acts via different mechanisms in malignant tumor cells and benign ECs. Of interest, we observed that linalool markedly increases the phosphorylation of ERK and inhibition of MEK/ERK signaling by PD0325901 largely reverses linalool-suppressed spheroid sprouting. This is an unexpected finding considering the fact that ERK signaling is widely accepted to promote EC survival and angiogenesis [42], although there are several studies indicating that ERK activation induces cell cycle arrest and apoptosis [5, 7].

Furthermore, we showed that linalool-induced intracellular ATP reduction and TRPM8 activation, but not ROS formation, contribute to the anti-angiogenic effect of linalool. Of interest, the intracellular ATP reduction promoted ERK phosphorylation. This view is supported by our results that (i) ATP supplementation completely reverses linalool-increased phosphorylated ERK and (ii) the inhibition of ERK phosphorylation has no effects on the reduction of intracellular ATP. In contrast, previous studies reported that extracellular ATP stimulates ERK signaling in several types of cells [43-45] and ATP depletion induced by anoxia reduces ERK phosphorylation [46]. These contradictory findings suggest a complex regulatory mechanism of ERK activation dependent on the intracellular level of ATP. As observed in our study, a slight intracellular ATP reduction may serve as a stimulus for the activation of ERK. On the other hand, the phosphorylation of ERK may not be possible under complete ATP deprivation due to the lack of the phosphate donor. The precise mechanism of how a slight intracellular ATP reduction causes ERK phosphorylation needs to be further elucidated. However, it is already known that the inhibitors of mitochondrial complex I rotenone and metformin, which reduce intracellular ATP levels, enhance ERK phosphorylation by promoting the dimerization of the kinase suppressor of Ras (KSR) with Raf, which catalyzes MEK phosphorylation [47]. Since linalool is also a mitochondrial complex I inhibitor [28], we therefore assume that it may induce ERK phosphorylation through regulating KSR-Raf dimerization.

In addition, we found that TRPM8 blockade has no influence on linalool-triggered ATP reduction and ERK phosphorylation. Moreover, ERK inhibition did not affect TRPM8 activity in linalool-treated HDMECs. These results demonstrate that linalool-induced TRPM8 activation is independent on intracellular ATP reduction and ERK phosphorylation. This view is further supported by our observation that linalool activates TRPM8 within seconds, while the linalool-induced phosphorylation of ERK requires a longer time span.

Finally, we investigated the mechanism of how linaloolinduced ERK phosphorylation inhibits angiogenesis. By performing a western blot-based small-scale expression screening of angiogenesis-regulatory proteins, we found that BMP-2 is downregulated by linalool-induced ERK phosphorylation. BMP-2 is a member of the transforming growth factor (TGF) superfamily. It has been reported to promote proliferation, migration and tube formation of several types of ECs [48-50]. In vivo, BMP-2 enhances angiogenesis in the mouse sponge assay and stimulates neovascularization in tumors formed from A549 and MCF-7 cells [48, 49]. Notably, several studies demonstrated that BMP-2 acts upstream of ERK $[48,51,52]$. On the other hand, it is well known that phosphorylated ERK translocates into the nucleus, where it regulates different transcription factors [30]. Therefore, it is reasonable that BMP-2 can also be influenced by linalool-induced ERK phosphorylation. In fact, previous studies have already shown that different compounds, including wedelolactone [53], fucoidan [54], imperatorin and bergapten [55], induce ERK phosphorylation in human mesenchymal stem cells or osteoblasts, which, in turn, regulates BMP-2 expression. Accordingly, it may be assumed that the herein observed BMP-2 downregulation 

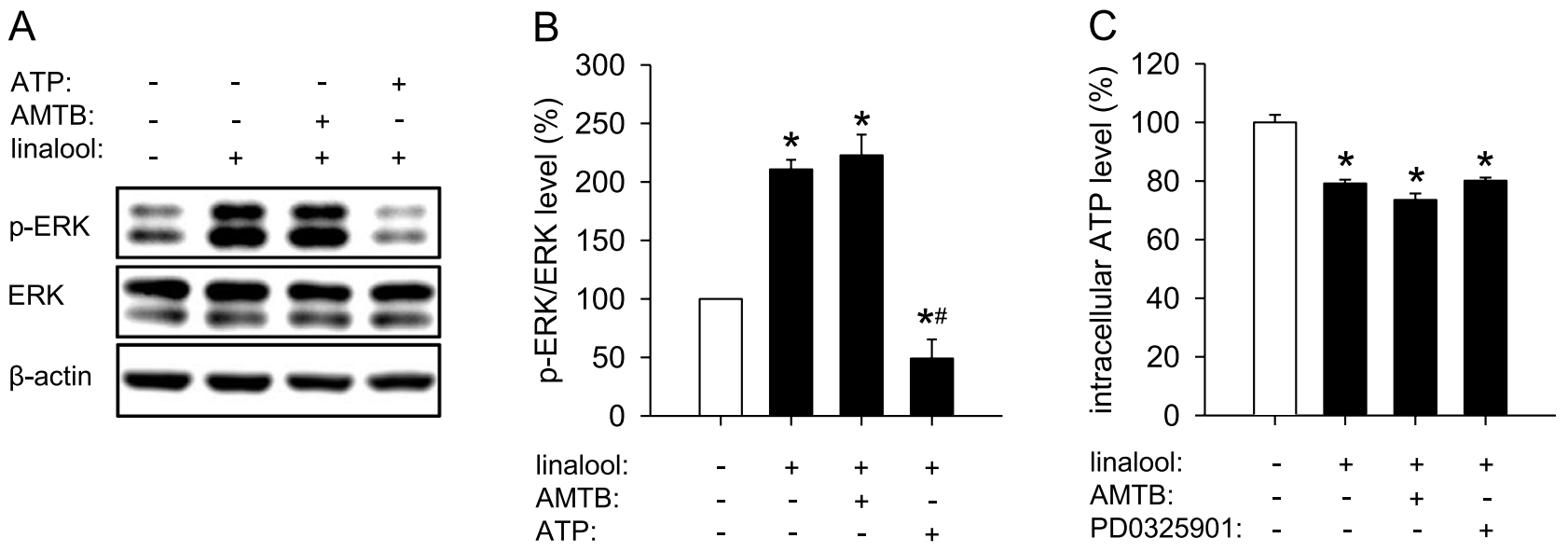

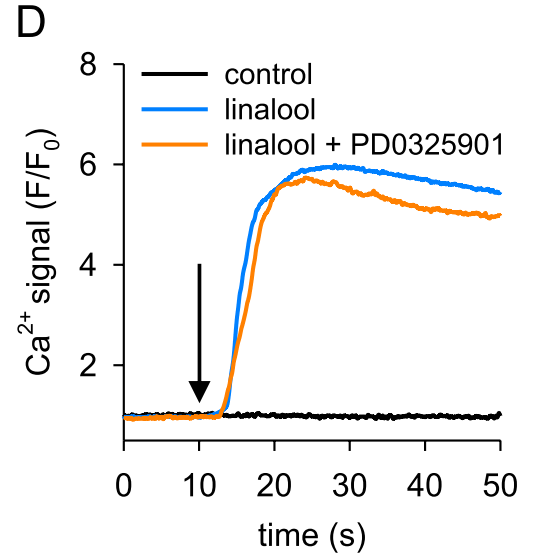

Fig. 7 Supplementation of ATP reverses linalool-induced ERK phosphorylation independently of TRPM8 activation. a Western blot of p-ERK, ERK and $\beta$-actin expression in HDMECs, which were pretreated for $2 \mathrm{~h}$ with or without $5 \mu \mathrm{M}$ AMTB or $1 \mathrm{mM}$ ATP and then exposed for $30 \mathrm{~min}$ to 0 or $2 \mathrm{mM}$ linalool. b Expression levels of pERK/ERK (in \% of $0 \mathrm{mM}$ linalool) as assessed by western blot ( $n=3$ independent experiments). c Intracellular ATP level (in $\%$ of $0 \mathrm{mM}$ linalool) of HDMECs, which were treated with 0 or 2 $\mathrm{mM}$ linalool in the presence or absence of $5 \mu \mathrm{M}$ AMTB or $1 \mu \mathrm{M}$

is induced by linalool-promoted ERK phosphorylation, and that this mediates the anti-angiogenic effect of linalool. We also demonstrated that the activation of TRPM8 channels triggered by linalool blocks $\beta 1$ integrin/FAK signaling. These results confirm the observation of Genova et al. that TRPM8 inhibits EC migration via a non-channel function by trapping Rap 1 intracellularly and consequently impairing integrin activation [8]. Hence, this ion channel is a promising novel target for anti-angiogenic therapy.

In summary, the present study demonstrates for the first time that linalool acts as an angiogenesis inhibitor by targeting multiple independent angiogenesis-related mediators (Fig. 9). This could be a major advantage of linalool

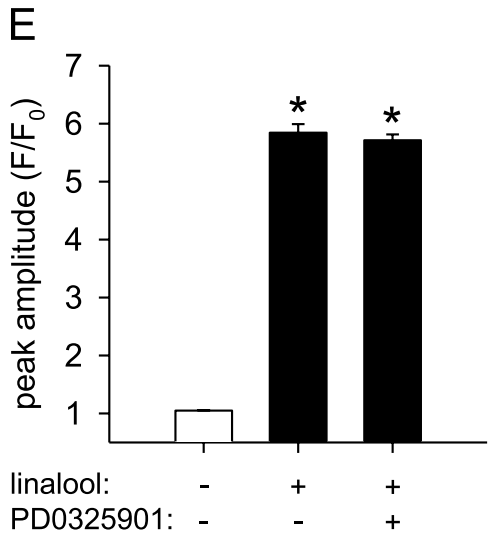

PD0325901, as assessed by the luciferase assay $(n=4)$. $\mathbf{d ~ \mathrm { Ca } ^ { 2 + }}$ signal $\left(F / F_{0}\right)$ in HDMECs, which were pretreated for $2 \mathrm{~h}$ with or without $1 \mu \mathrm{M}$ PD0325901, loaded with Fluo-4 AM and then stimulated with 0 or $2 \mathrm{mM}$ linalool. The onset of stimulation is indicated by a black arrow. e Peak amplitude $\left(F / F_{0}\right)$ of $\mathrm{Ca}^{2+}$ signal in HDMECs, which were pretreated with or without PD0325901, loaded with Fluo-4 AM and then stimulated with vehicle or linalool. Means \pm SEM. $* P<0.05$ vs. $0 \mathrm{mM}$ linalool. ${ }^{\#} P<0.05$ vs. $2 \mathrm{mM}$ linalool

compared to highly selective anti-angiogenic agents, because this pleiotropic action profile may prevent cellular escape mechanisms. Accordingly, linalool may represent a promising therapeutic agent or a lead compound for the future treatment of angiogenesis-related diseases. However, it should be considered that, like other phytochemicals, linalool exhibits a low in vivo bioavailability. Hence, it will be necessary to develop sophisticated carrier systems and novel derivatives or prodrugs to improve the pharmacokinetic properties of the compound. Rapid progress in modern drug design and nanotechnology may markedly contribute to achieve this in the future. 

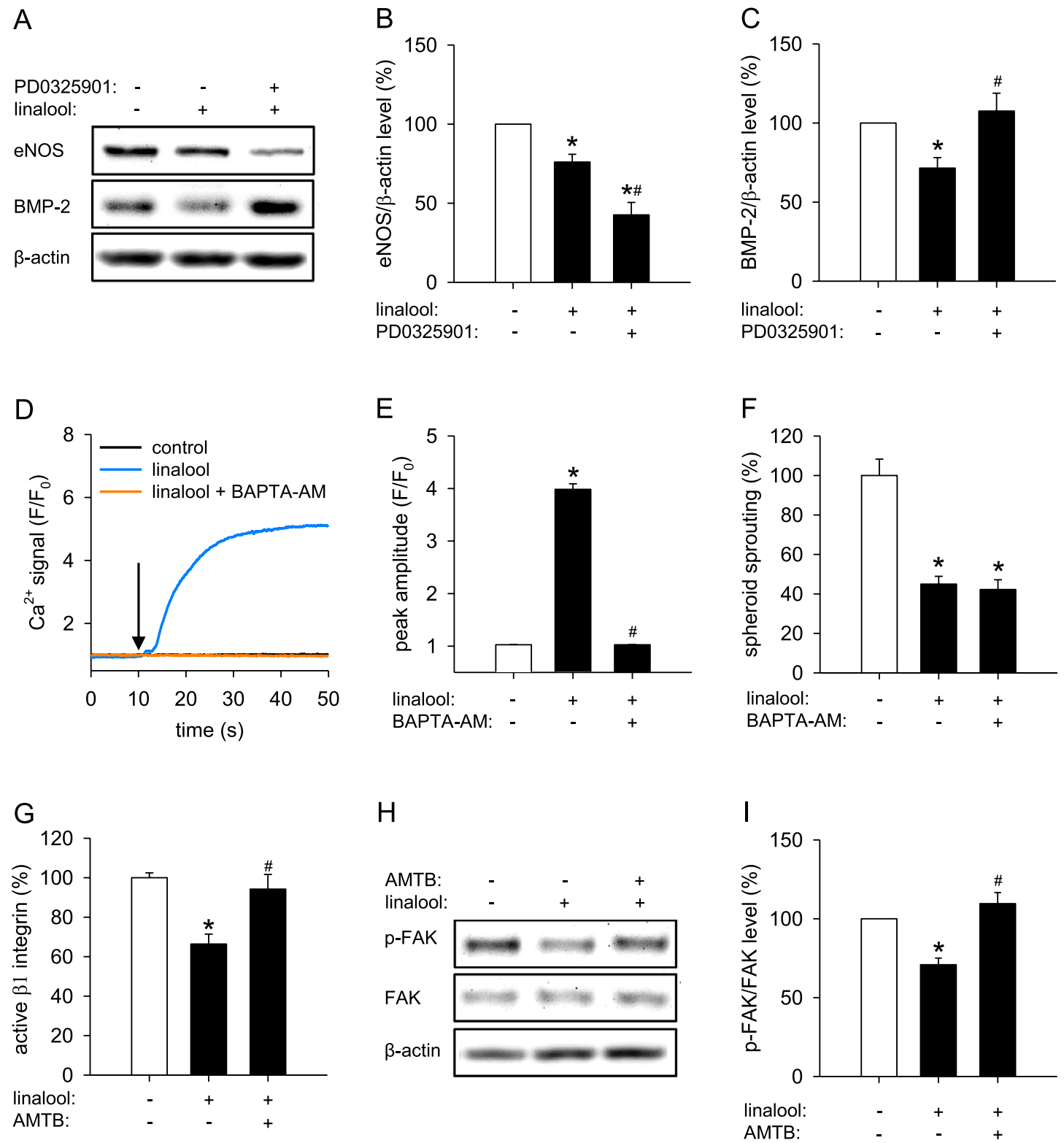

Fig. 8 Linalool downregulates BMP-2 by phosphorylating ERK and inhibits $\beta 1$ integrin/FAK signaling by activating TRPM8. a Western blot of eNOS, BMP-2 and $\beta$-actin expression in HDMECs, which were pretreated for $2 \mathrm{~h}$ with or without $1 \mu \mathrm{M}$ PD0325901 and then exposed for $30 \mathrm{~min}$ to 0 or $2 \mathrm{mM}$ linalool. b, $\mathbf{c}$ Expression levels of eNOS $/ \beta$-actin (b) and BMP- $2 / \beta$-actin (c) (in $\%$ of $0 \mathrm{mM}$ linalool) as assessed by western blot ( $n=4$ independent experiments). d Ca ${ }^{2+}$ signal $\left(F / F_{0}\right)$ in HDMECs, which were pretreated with or without $2.5 \mu$ M BAPTA-AM (a selective $\mathrm{Ca}^{2+}$ chelator) for $2 \mathrm{~h}$, loaded with Fluo-4 AM and then stimulated with 0 or $2 \mathrm{mM}$ linalool. The onset of stimulation is indicated by a black arrow. e Peak amplitude $\left(F / F_{0}\right)$ of $\mathrm{Ca}^{2+}$ signal in HDMECs, which were pretreated with or without BAPTA-AM, loaded with Fluo-4 AM and then stimulated with vehicle or linalool. f Sprouting (in $\%$ of $0 \mathrm{mM}$ linalool) of HDMEC spheroids, which were treated for $24 \mathrm{~h}$ with 0 or $2 \mathrm{mM}$ linalool in the presence or absence of $2.5 \mu \mathrm{M}$ BAPTA-AM, as assessed by the spheroid sprouting assay $(n=10)$. g Active $\beta 1$ integrin (in $\%$ of $0 \mathrm{mM}$ linalool) in HDMECs, which were pretreated for $2 \mathrm{~h}$ with or without $5 \mu \mathrm{M}$ AMTB and then exposed for $30 \mathrm{~min}$ to 0 or $2 \mathrm{mM}$ linalool, as assessed by flow cytometry $(n=3)$. h Western blot of p-FAK, FAK and $\beta$-actin expression in HDMECs, which were pretreated for $2 \mathrm{~h}$ with or without $5 \mu \mathrm{M}$ AMTB and then exposed for $30 \mathrm{~min}$ to 0 or 2 $\mathrm{mM}$ linalool. i Expression levels of pFAK/FAK (in \% of $0 \mathrm{mM}$ linalool) as assessed by western blot ( $n=4$ independent experiments). Means \pm SEM. ${ }^{*} P<0.05$ vs. $0 \mathrm{mM}$ linalool. ${ }^{\#} P<0.05$ vs. $2 \mathrm{mM}$ linalool 


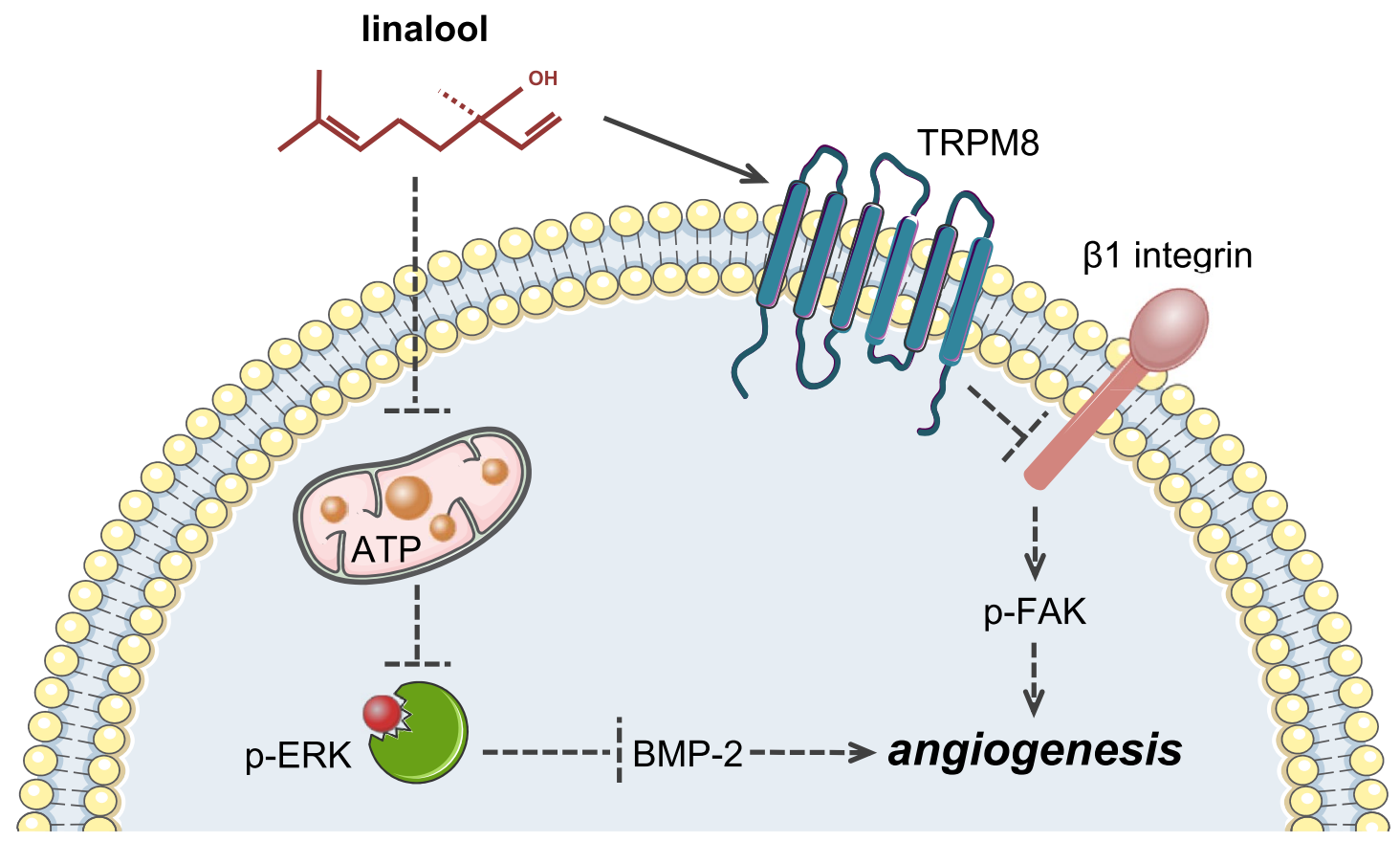

Fig. 9 Schematic diagram of molecular mechanisms underlying the inhibitory effect of linalool on angiogenesis

Supplementary Information The online version contains supplementary material available at https://doi.org/10.1007/s10456-021-09772-y.

Acknowledgements We are grateful for the excellent technical assistance of Janine Becker, Caroline Bickelmann, Christina Marx, Julia Parakenings and Ruth M. Nickels (Institute for Clinical \& Experimental Surgery, Saarland University, Germany). Figure 9 contains graphic elements from Servier Medical Art (http://smart.servier.com/), licensed under a Creative Common Attribution 3.0 Generic License.

Funding Open Access funding enabled and organized by Projekt DEAL.

Open Access This article is licensed under a Creative Commons Attribution 4.0 International License, which permits use, sharing, adaptation, distribution and reproduction in any medium or format, as long as you give appropriate credit to the original author(s) and the source, provide a link to the Creative Commons licence, and indicate if changes were made. The images or other third party material in this article are included in the article's Creative Commons licence, unless indicated otherwise in a credit line to the material. If material is not included in the article's Creative Commons licence and your intended use is not permitted by statutory regulation or exceeds the permitted use, you will need to obtain permission directly from the copyright holder. To view a copy of this licence, visit http://creativecommons.org/licenses/by/4.0/.

\section{References}

1. Hoeben A, Landuyt B, Highley MS, Wildiers H, Van Oosterom AT, De Bruijn EA (2004) Vascular endothelial growth factor and angiogenesis. Pharmacol Rev 56(4):549-580. https://doi. org/10.1124/pr.56.4.3
2. Karar J, Maity A (2011) PI3K/AKT/mTOR pathway in angiogenesis. Front Mol Neurosci 4:51. https://doi.org/10.3389/fnmol .2011 .00051

3. Liu W, Liu Y, Lowe WL Jr (2001) The role of phosphatidylinositol 3-kinase and the mitogen-activated protein kinases in insulin-like growth factor-I-mediated effects in vascular endothelial cells. Endocrinology 142(5):1710-1719. https:// doi.org/10.1210/endo.142.5.8136

4. Aikawa R, Komuro I, Yamazaki T, Zou Y, Kudoh S, Tanaka M, Shiojima I, Hiroi Y, Yazaki Y (1997) Oxidative stress activates extracellular signal-regulated kinases through Src and Ras in cultured cardiac myocytes of neonatal rats. J Clin Investig 100(7):1813-1821. https://doi.org/10.1172/JCI119709

5. Lu Z, Xu S (2006) ERK1/2 MAP kinases in cell survival and apoptosis. IUBMB Life 58(11):621-631. https://doi. org/10.1080/15216540600957438

6. Ng DC, Bogoyevitch MA (2000) The mechanism of heat shock activation of ERK mitogen-activated protein kinases in the interleukin 3-dependent ProB cell line BaF3. J Biol Chem 275(52):40856-40866. https://doi.org/10.1074/jbc.M0046 39200

7. Tang D, Wu D, Hirao A, Lahti JM, Liu L, Mazza B, Kidd VJ, Mak TW, Ingram AJ (2002) ERK activation mediates cell cycle arrest and apoptosis after DNA damage independently of p53. J Biol Chem 277(15):12710-12717. https://doi.org/10.1074/jbc.M1115 98200

8. Genova T, Grolez GP, Camillo C, Bernardini M, Bokhobza A, Richard E, Scianna M, Lemonnier L, Valdembri D, Munaron L, Philips MR, Mattot V, Serini G, Prevarskaya N, Gkika D, Pla AF (2017) TRPM8 inhibits endothelial cell migration via a nonchannel function by trapping the small GTPase Rap1. J Cell Biol 216(7):2107-2130. doi:https://doi.org/10.1083/jcb.201506024

9. Yin Y, Le SC, Hsu AL, Borgnia MJ, Yang H, Lee SY (2019) Structural basis of cooling agent and lipid sensing by the coldactivated TRPM8 channel. Science. https://doi.org/10.1126/scien ce.aav9334 
10. McKemy DD, Neuhausser WM, Julius D (2002) Identification of a cold receptor reveals a general role for TRP channels in thermosensation. Nature 416(6876):52-58. https://doi.org/10.1038/ nature719

11. Brauchi S, Orio P, Latorre R (2004) Clues to understanding cold sensation: thermodynamics and electrophysiological analysis of the cold receptor TRPM8. Proc Natl Acad Sci USA 101(43):15494-15499. https://doi.org/10.1073/pnas.0406773101

12. Fiorio Pla A, Gkika D (2013) Emerging role of TRP channels in cell migration: from tumor vascularization to metastasis. Front Physiol 4:311. https://doi.org/10.3389/fphys.2013.00311

13. Yoo SY, Kwon SM (2013) Angiogenesis and its therapeutic opportunities. Mediat Inflamm 2013:127170. https://doi. org/10.1155/2013/127170

14. Biel NM, Siemann DW (2016) Targeting the Angiopoietin-2/Tie-2 axis in conjunction with VEGF signal interference. Cancer Lett 380(2):525-533. https://doi.org/10.1016/j.canlet.2014.09.035

15. Aprotosoaie AC, Hancianu M, Costache II, Miron A (2014) Linalool: a review on a key odorant molecule with valuable biological properties. Flavour Fragr J 29(4):193-219. https://doi. org/10.1002/ffj.3197

16. Hussain AI, Anwar F, Hussain Sherazi ST, Przybylski R (2008) Chemical composition, antioxidant and antimicrobial activities of basil (Ocimum basilicum) essential oils depends on seasonal variations. Food Chem 108(3):986-995. https://doi.org/10.1016/j. foodchem.2007.12.010

17. Peana AT, D’Aquila PS, Panin F, Serra G, Pippia P, Moretti MD (2002) Anti-inflammatory activity of linalool and linalyl acetate constituents of essential oils. Phytomed Int J Phytother Phytopharmacol 9(8):721-726. https://doi.org/10.1078/094471102321621 322

18. Gu Y, Scheuer C, Feng D, Menger MD, Laschke MW (2013) Inhibition of angiogenesis: a novel antitumor mechanism of the herbal compound arctigenin. Anticancer Drugs 24(8):781-791. https://doi.org/10.1097/CAD.0b013e328362fb84

19. Gu Y, Ampofo E, Menger MD, Laschke MW (2017) miR-191 suppresses angiogenesis by activation of NF-kappaB signaling. FASEB J 31(8):3321-3333. https://doi.org/10.1096/fj.20160 $1263 R$

20. Gu Y, Korbel C, Scheuer C, Nenicu A, Menger MD, Laschke MW (2016) Tubeimoside-1 suppresses tumor angiogenesis by stimulation of proteasomal VEGFR2 and Tie2 degradation in a non-small cell lung cancer xenograft model. OncoTarget 7(5):5258-5272. https://doi.org/10.18632/oncotarget.6676

21. Hui X, Reither G, Kaestner L, Lipp P (2014) Targeted activation of conventional and novel protein kinases $\mathrm{C}$ through differential translocation patterns. Mol Cell Biol 34(13):2370-2381. https:// doi.org/10.1128/MCB.00040-14

22. Cheng Y, Dai C, Zhang J (2017) SIRT3-SOD2-ROS pathway is involved in linalool-induced glioma cell apoptotic death. Acta Biochim Pol 64(2):343-350. https://doi.org/10.18388/ abp.2016_1438

23. Rodenak-Kladniew B, Castro A, Starkel P, De Saeger C, Garcia de Bravo M, Crespo R (2018) Linalool induces cell cycle arrest and apoptosis in HepG2 cells through oxidative stress generation and modulation of Ras/MAPK and Akt/mTOR pathways. Life Sci 199:48-59. https://doi.org/10.1016/j.lfs.2018.03.006

24. Incalza MA, D’Oria R, Natalicchio A, Perrini S, Laviola L, Giorgino F (2018) Oxidative stress and reactive oxygen species in endothelial dysfunction associated with cardiovascular and metabolic diseases. Vasc Pharmacol 100:1-19. https://doi. org/10.1016/j.vph.2017.05.005

25. Sauer H, Gunther J, Hescheler J, Wartenberg M (2000) Thalidomide inhibits angiogenesis in embryoid bodies by the generation of hydroxyl radicals. Am J Pathol 156(1):151-158. https://doi. org/10.1016/S0002-9440(10)64714-1
26. Kim GD, Oh J, Park HJ, Bae K, Lee SK (2013) Magnolol inhibits angiogenesis by regulating ROS-mediated apoptosis and the PI3K/ AKT/mTOR signaling pathway in $\mathrm{mES} / \mathrm{EB}$-derived endotheliallike cells. Int J Oncol 43(2):600-610. https://doi.org/10.3892/ ijo.2013.1959

27. Yee EMH, Brandl MB, Pasquier E, Cirillo G, Kimpton K, Kavallaris M, Kumar N, Vittorio O (2017) Dextran-Catechin inhibits angiogenesis by disrupting copper homeostasis in endothelial cells. Sci Rep 7(1):7638. https://doi.org/10.1038/s41598-01707452-w

28. Usta J, Kreydiyyeh S, Knio K, Barnabe P, Bou-Moughlabay Y, Dagher S (2009) Linalool decreases HepG2 viability by inhibiting mitochondrial complexes I and II, increasing reactive oxygen species and decreasing ATP and GSH levels. Chem Biol Interact 180(1):39-46. https://doi.org/10.1016/j.cbi.2009.02.012

29. Behrendt HJ, Germann T, Gillen C, Hatt H, Jostock R (2004) Characterization of the mouse cold-menthol receptor TRPM8 and vanilloid receptor type-1 VR1 using a fluorometric imaging plate reader (FLIPR) assay. Br J Pharmacol 141(4):737-745. https:// doi.org/10.1038/sj.bjp.0705652

30. Liu F, Yang X, Geng M, Huang M (2018) Targeting ERK, an Achilles' Heel of the MAPK pathway, in cancer therapy. Acta Pharm Sin B 8(4):552-562. https://doi.org/10.1016/j. apsb.2018.01.008

31. Noskova K, Dovrtelova G, Zendulka O, Reminek R, Jurica J (2016) The effect of (-)-linalool on the metabolic activity of liver CYP enzymes in rats. Physiol Res 65(Supplementum 4):S499-S504

32. Cerchiara T, Straface SV, Brunelli E, Tripepi S, Gallucci MC, Chidichimo G (2015) Antiproliferative effect of linalool on RPMI 7932 human melanoma cell line: ultrastructural studies. Nat Prod Commun 10(4):547-549

33. Chang MY, Shieh DE, Chen CC, Yeh CS, Dong HP (2015) Linalool induces cell cycle arrest and apoptosis in leukemia cells and cervical cancer cells through CDKIs. Int J Mol Sci 16(12):2816928179. https://doi.org/10.3390/ijms161226089

34. Cherng JM, Shieh DE, Chiang W, Chang MY, Chiang LC (2007) Chemopreventive effects of minor dietary constituents in common foods on human cancer cells. Biosci Biotechnol Biochem 71(6):1500-1504. doi:https://doi.org/10.1271/bbb.70008

35. Iwasaki K, Zheng YW, Murata S, Ito H, Nakayama K, Kurokawa T, Sano N, Nowatari T, Villareal MO, Nagano YN, Isoda H, Matsui $\mathrm{H}$, Ohkohchi $\mathrm{N}$ (2016) Anticancer effect of linalool via cancerspecific hydroxyl radical generation in human colon cancer. World J Gastroenterol 22(44):9765-9774. https://doi.org/10.3748/wjg. v22.i44.9765

36. Xing X, Ma JH, Fu Y, Zhao H, Ye XX, Han Z, Jia FJ, Li X (2019) Essential oil extracted from Erythrina corallodendron L. leaves inhibits the proliferation, migration, and invasion of breast cancer cells. Medicine 98(36):e17009. https://doi.org/10.1097/MD.00000 00000017009

37. Eilken HM, Adams RH (2010) Dynamics of endothelial cell behavior in sprouting angiogenesis. Curr Opin Cell Biol 22(5):617-625. https://doi.org/10.1016/j.ceb.2010.08.010

38. Nicosia RF (2009) The aortic ring model of angiogenesis: a quarter century of search and discovery. J Cell Mol Med 13(10):41134136. https://doi.org/10.1111/j.1582-4934.2009.00891.x

39. Staton CA, Reed MW, Brown NJ (2009) A critical analysis of current in vitro and in vivo angiogenesis assays. Int J Exp Pathol 90(3):195-221. https://doi.org/10.1111/j.1365-2613.2008.00633 . $\mathrm{x}$

40. Auerbach R, Lewis R, Shinners B, Kubai L, Akhtar N (2003) Angiogenesis assays: a critical overview. Clin Chem 49(1):32-40. https://doi.org/10.1373/49.1.32

41. Pan W, Zhang G (2019) Linalool monoterpene exerts potent antitumor effects in OECM 1 human oral cancer cells by inducing 
sub-G1 cell cycle arrest, loss of mitochondrial membrane potential and inhibition of PI3K/AKT biochemical pathway. J BUON Off J Balk Union Oncol 24(1):323-328

42. Shin M, Beane TJ, Quillien A, Male I, Zhu LJ, Lawson ND (2016) Vegfa signals through ERK to promote angiogenesis, but not artery differentiation. Development 143(20):3796-3805. https:// doi.org/10.1242/dev.137919

43. Chang SJ, Tzeng CR, Lee YH, Tai CJ (2008) Extracellular ATP activates the PLC/PKC/ERK signaling pathway through the $\mathrm{P} 2 \mathrm{Y} 2$ purinergic receptor leading to the induction of early growth response 1 expression and the inhibition of viability in human endometrial stromal cells. Cell Signal 20(7):1248-1255. https:// doi.org/10.1016/j.cellsig.2008.02.011

44. Swanson KD, Reigh C, Landreth GE (1998) ATP-stimulated activation of the mitogen-activated protein kinases through ionotrophic $\mathrm{P} 2 \times 2$ purinoreceptors in PC12 cells. Difference in purinoreceptor sensitivity in two PC12 cell lines. J Biol Chem 273(32):19965-19971. https://doi.org/10.1074/jbc.273.32.19965

45. Wagstaff SC, Bowler WB, Gallagher JA, Hipskind RA (2000) Extracellular ATP activates multiple signalling pathways and potentiates growth factor-induced c-fos gene expression in MCF-7 breast cancer cells. Carcinogenesis 21(12):2175-2181. https://doi. org/10.1093/carcin/21.12.2175

46. Abas L, Bogoyevitch MA, Guppy M (2000) Mitochondrial ATP production is necessary for activation of the extracellular signalregulated kinases during ischaemia/reperfusion in rat myocytederived H9c2 cells. Biochem J 349(Pt 1):119-126. https://doi. org/10.1042/0264-6021:3490119

47. Verlande A, Krafcikova M, Potesil D, Trantirek L, Zdrahal Z, Elkalaf M, Trnka J, Soucek K, Rauch N, Rauch J, Kolch W, Uldrijan S (2018) Metabolic stress regulates ERK activity by controlling KSR-RAF heterodimerization. EMBO Rep 19(2):320-336. https://doi.org/10.15252/embr.201744524

48. Langenfeld EM, Langenfeld J (2004) Bone morphogenetic protein-2 stimulates angiogenesis in developing tumors. Mol Cancer Res 2(3):141-149

49. Raida M, Clement JH, Leek RD, Ameri K, Bicknell R, Niederwieser D, Harris AL (2005) Bone morphogenetic protein 2
(BMP-2) and induction of tumor angiogenesis. J Cancer Res Clin Oncol 131(11):741-750. https://doi.org/10.1007/s0043 2-005-0024-1

50. Finkenzeller G, Hager S, Stark GB (2012) Effects of bone morphogenetic protein 2 on human umbilical vein endothelial cells. Microvasc Res 84(1):81-85. https://doi.org/10.1016/j. mvr.2012.03.010

51. Chen WC, Chung CH, Lu YC, Wu MH, Chou PH, Yen JY, Lai YW, Wang GS, Liu SC, Cheng JK, Wu YJ, Yeh HI, Wang LY, Wang SW (2018) BMP-2 induces angiogenesis by provoking integrin alpha6 expression in human endothelial progenitor cells. Biochem Pharmacol 150:256-266. https://doi.org/10.1016/j. bcp.2018.02.021

52. Jun JH, Yoon WJ, Seo SB, Woo KM, Kim GS, Ryoo HM, Baek JH (2010) BMP2-activated Erk/MAP kinase stabilizes Runx2 by increasing p300 levels and histone acetyltransferase activity. J Biol Chem 285(47):36410-36419. https://doi.org/10.1074/jbc. M110.142307

53. Zhu D, Deng X, Han XF, Sun XX, Pan TW, Zheng LP, Liu YQ (2018) Wedelolactone enhances osteoblastogenesis through ERKand JNK-mediated BMP2 expression and Smad/1/5/8 phosphorylation. Molecules. https://doi.org/10.3390/molecules23030561

54. Kim BS, Kang HJ, Park JY, Lee J (2015) Fucoidan promotes osteoblast differentiation via JNK- and ERK-dependent BMP2-Smad 1/5/8 signaling in human mesenchymal stem cells. Exp Mol Med 47:e128. https://doi.org/10.1038/emm.2014.95

55. Tang CH, Yang RS, Chien MY, Chen CC, Fu WM (2008) Enhancement of bone morphogenetic protein-2 expression and bone formation by coumarin derivatives via $\mathrm{p} 38$ and ERK-dependent pathway in osteoblasts. Eur J Pharmacol 579(1-3):40-49. https://doi.org/10.1016/j.ejphar.2007.10.013

Publisher's note Springer Nature remains neutral with regard to jurisdictional claims in published maps and institutional affiliations. 